based on water is difficult for effective absorption of solar energy.

To improve fluid optical properties, some nanostructures and nanoparticles (NPs) are added to working fluids that are directly exposed to incoming solar irradiance $[4,5,9-11]$. In recent years, it has been shown that mixing NPs in a fluid has a dramatic effect on its optical properties and considerably improves the optical and photothermal conversion properties of working transparent fluids with formation of nanofluids (NFs).

Important advances in nanotechnology led to production of different types of NPs with various structures, sizes and shapes [12-14], which have been demonstrated their great and immense potential. Optical properties of NFs are of great importance particularly for their use in volumetric direct absorbers. It is important because the selection of NPs can result in a significant improvement in the absorption of NFs in the ultraviolet (UV), visible (VIS) and infrared (IR) electromagnetic spectrum regions.

Optical properties of various types of NPs are actively investigated in recent years [13-22]. These investigations were concentrated on UV, VIS and near-IR spectral intervals for laser and optical sources and their applications. The investigations of NP optical properties have received additional impulse after the commencement of the NPs use for solar radiation absorption applications. It needs to investigate more wide spectral interval than it was investigated before with some specific requests on the NPs properties.

Successful applications of NPs for effective absorption of optical radiation are strongly connected with the socalled surface plasmon resonance of radiation on nanosphere and a NP absorbs and scatters radiation energy well at resonance wavelength [13-22]. The design of NPs with chosen and adjusted plasmonic and thermo-optical properties is possible by the selection of the materials, material composition and geometrical properties (sizes) of NP including the attempts to search for novel and

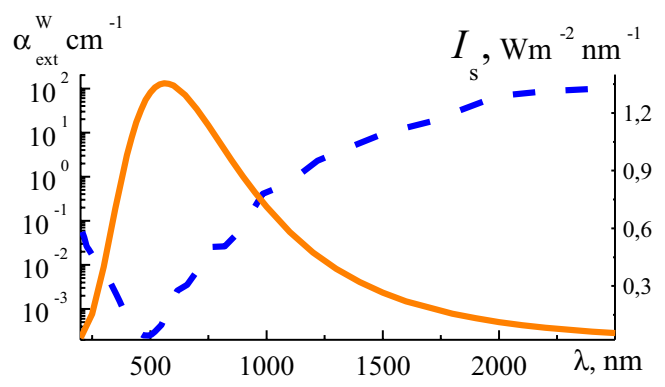

Fig. 1 The dependence of radiation extinction coefficient by water (dashed, blue) and solar irradiance $I_{\mathrm{S}}$ (solid, orange) on radiation wavelength $\lambda$ better plasmonic NPs and the achievements of "ideal" optical characteristics [23-25].

It is possible to realize excellent optical properties of NPs on the basis of manipulation of NP plasmon resonance. But the essential information is now limited and separated results of the applications of various NPs do not present whole picture.

The selection of NPs optical properties should provide the maximal heating of NPs and NF. Effective maximal heating of both NP itself and the ambient fluid by solar radiation, the conversion of absorbed energy into thermal energy and intensive thermal energy transfer from NPs to NF are determined by high absorption and small scattering of radiation by NPs [13-22]. Radiation scattering is concurrent and parasitic process and leads to the following multiple processes of absorption and scattering and decreasing the absorption efficiency. Unfortunately, up-to-date publications represent critical missing data in the field of solar heating of NPs.

Novel approaches for solar energy conversion are presented below. The analysis of novel heating model has been presented that correctly describes the temperature dynamics of heating of NPs and fluid by solar radiation, and in particular, this model allows us to select appropriate optical properties of NPs. To date, the works in this area have been limited but their results demonstrate that selective solar-absorbing NPs can be designed and produced.

This review presents a comprehensive modern review of the optical properties of spherical metallic, oxide and metal core-its oxide shell NPs, placed in water, and solar thermal conversion of absorbed energy by NPs. This review is concentrated on the recent studies and achievements mostly during 2016-2018 years naturally taking into account the base papers from previous years. Carbon NPs, nanotubes, have been investigated and reviewed [26-28], and they are out of our review.

\section{Optical properties of metallic nanoparticles}

\subsection{Analysis of optical properties of metallic nanoparticles}

Among various NPs, metallic NPs are of special interest for solar energy applications because of their prominent plasmonic (absorption) and thermo-optical properties. The plasmonic and optical properties of metallic NPs were previously investigated for optical and laser applications in the narrow spectral interval 300-1000 nm [13-25]. Some of these results can be used for NP solar applications with serious limitations because of the absence of spectral interval $1000-2500 \mathrm{~nm}$. Main parameters of the 
NP optical investigations [29-50] for the purposes of solar applications, including NP metal, size, spectral interval and used methods of investigations, surrounding liquid, are presented in Table 1. Theoretical investigations of absorption, scattering, extinction and scattering indicatrices of radiation by various NPs have been carried out on the basis of Mie theory [29-35, 37, 38, 41-43, 46, 50], DDA [36] and FDTD [39] methods. Experimental investigations of NP optical properties used dark-field microspectrometer, optical and transmittance spectroscopy, etc.

Au NPs were immersed in water and oil, maximal ranges of investigated diameters were $d_{0}=5-250 \mathrm{~nm}$, and spectral interval was $250-2500 \mathrm{~nm}$ [29-39]. It was found the shift of plasmon resonance wavelength to larger values of $\lambda$ with increasing NP diameters. The estimation of the size distribution of the metallic NPs was obtained through the fitting of the extinction spectra via Mie theory [31]. The investigation of plasmonic absorption and scattering properties of metallic NPs in the spectral interval $250-2500 \mathrm{~nm}$ for NP radii $r_{0}=25,50,75 \mathrm{~nm}$ has been carried out [30, 33, 37]. Spherical gold, aluminum, silver and copper NPs with diameters $20-140 \mathrm{~nm}$ were theoretically investigated for the wavelength range $300-1350 \mathrm{~nm}$ [38]. Comparative analysis has been performed for the absorption properties of noble metallic NPs ( $\mathrm{Au}, \mathrm{Ag}, \mathrm{Cu}$ and $\mathrm{Al}$ ) to determine suitable parameters for effective solar heating [39].

Experimental dark-field microspectrometer measured quantitative spectral scattering cross sections of $\mathrm{Au}$ NPs for comparison with computer results [29]. The link between optical properties and photothermal conversion efficiencies for gold NPs is theoretically and experimentally investigated [32-36]. The results indicate that the photothermal efficiencies of gold NPs are size tunable, and their variation can be correlated with the absorption/ extinction ratios [32], and it is higher for gold NFs than that of pure water [34]. Good agreement of the modeling results was observed with the experimental data except spectral interval of $600-800 \mathrm{~nm}$, which they attributed to the existence of large aggregates in the NFs. The optical properties and photothermal conversion efficiencies for Au NPs were experimentally (UV-VIS spectroscopy) and theoretically (DDA) investigated with good agreement between experimental and theoretical results $[35,36]$.

Ag NPs were immersed in water, therminol, DI water and $E G$, maximal ranges of investigated diameters were $d_{0}=10-1000 \mathrm{~nm}$, and spectral interval was $250-2500 \mathrm{~nm}$ (see Table 1). Experimental investigations of Ag NPs include the spectroscopic measurements of extinction coefficients over wavelengths that are important for solar energy (250-2500 nm) [40]. Transmittance of Ag NPs with nominal size of 35-1000 nm dispersed in base fluid has been measured, and the results reasonably well match the theoretical transmittance data [42]. It was noted that the effect of agglomeration played a significant role in determining the resulting transmittance of the silver NP suspensions. A combined numerical and experimental study has been conducted on a NF direct absorption collector utilizing silver NPs dispersed in deionizing water [43]. The optical properties measurement of NFs showed remarkable enhancement even at low particle concentration. The formation of plasmon high-order resonances (quadrupolar and more) with an increase in NP sizes up to $250 \mathrm{~nm}$ is very interesting possibility for the use of these features in solar absorption radiation $[33,41]$.

Al NPs experimentally and theoretically have been investigated [30, 37-40, 44, 45]. Aluminum NPs show very strong extinction coefficient at shorter wavelength and peak at $0.3 \mathrm{~nm}[37,44]$. It should be noted join results for $\mathrm{Ag}$ and AI NFs. The Rayleigh scattering approach for these metal NFs has differences with experimental data, because of agglomeration of NPs as well as the formation of oxide layer in metallic NPs [40]. The same situation exists for Mie solution also because of agglomeration phenomenon [45].

The radiation transmission characteristics of Ni NPs have been investigated by spectroscopic measurement [46]. The radiation properties of the ionic liquid NFs containing $\mathrm{Ni}$ and $\mathrm{Cu}$ NPs were investigated by the experimental and theoretical (Rayleigh) methods [47]. The model fails to accurately predict the extinction coefficients in the wavelength below $1250 \mathrm{~nm}$, especially for Ni and Cu NPs, due to their possible surface oxidation. The investigation of plasmonic absorption and scattering properties of metallic Ni NPs has been carried out $[33,37]$ for radiation wavelengths in the spectral interval $250-2500 \mathrm{~nm}$ for NP radii $r_{0}=25,50,75 \mathrm{~nm}$.

$\mathrm{Cu}$ NPs have attracted a lot of interests in recent years due to their interesting properties, low-cost preparation and many potential applications in solar energy absorption [30, 37-39, 47-49]. Transmission electron microscopy and UV-VIS spectrometry of the Cu NPs, immersed in polyethylene glycol (PEG), have been investigated [48]. The transmittance of water-based Cu NFs at different volume fractions over solar spectrum was measured by the UV-VIS-NIR spectrophotometer based on integrating sphere principle [49], and the transmittance decreases with increasing NP size, mass fraction and optical depth.

Optical properties $\mathrm{Ti}, \mathrm{Ni}, \mathrm{Mo}, \mathrm{Zn}$ and Co NPs with the radii in the range from 25 to $75 \mathrm{~nm}$ were analyzed in the whole solar spectrum [33,37]. Indicatrices of light scattering by homogeneous metallic $\mathrm{Ti}$, Ni and $\mathrm{Zn} \mathrm{NPs}$ with radii of $r_{0}=50,75,100 \mathrm{~nm}$ are calculated numerically for wavelengths of $\lambda=300,560$ and $1000 \mathrm{~nm}$ [50]. It needs the selection of appropriate NPs for application in solar absorption on the basis of theoretical and experimental investigations. 
Table 1 Optical properties of spherical metallic NPs

\begin{tabular}{|c|c|c|c|c|}
\hline References & NP material, fluid & NP size, $d_{0}(\mathrm{~nm})$ & Spectral interval (nm) & $\begin{array}{l}\text { Th-theory (method), Exp- } \\
\text { experiment, results }\end{array}$ \\
\hline & $A u$ & & & \\
\hline Anderson et al. [29] & Oil & 99,109 & $400-900$ & Th (Mie)+ Exp, scat. \\
\hline Pustovalov et al. [30] & Water & $10-250$ & $250-1100$ & Th (Mie)-abs., scat., ext. \\
\hline Moreira et al. [31] & Water & $48-90$ & $250-800$ & Th (Mie)+ Exp, ext \\
\hline Jiang et al. [32] & Water & $5-50$ & $300-800$ & Th (Mie)+ Exp, ext. \\
\hline Pustovalov et al. [33] & Water & $50,100,150$ & $250-2500$ & Th (Mie)-abs., scat., ext. \\
\hline Jin et al. [34] & Water & $9-120$ & $300-1000$ & Th (Mie)+ Exp, absorbance \\
\hline Chen et al. [35] & Water & $25-40$ & $300-1000$ & Th (Mie)+ Exp, absorbance \\
\hline Qin et al. [36] & Water & $15-100$ & $400-1000$ & Th (DDA)+ Exp, ext. \\
\hline Astafyeva et al. [37] & Water & $20,50,100$ & $300-1000$ & Th (Mie)- abs., scat., ext, indicatr. \\
\hline Holm et al. [38] & Water & $20-140$ & $300-1350$ & Th (Mie)-abs., scat., ext. \\
\hline \multirow[t]{2}{*}{ Chen et al. [39] } & Water & $20-100$ & $300-1200$ & Th (FDTD)- abs., scat., ext. \\
\hline & $\mathrm{Ag}$ & & & \\
\hline Taylor et al. [40] & Water, Thermin. & $40-250$ & $250-2500$ & Th (Rayl)+ Exp, extinction \\
\hline Pustovalov et al. [30] & Water & $10-250$ & $250-1100$ & Th (Mie)- abs., scat., ext \\
\hline Moreira et al. [31] & Water & $10-28$ & $250-800$ & Th (Mie)+ Exp, ext \\
\hline Pustovalov et al. [41] & Water & $10-250$ & $355-1064$ & Th (Mie)-abs., scat., ext. \\
\hline Otanicar et al. [42] & Water, EG & 35,1000 & $300-1300$ & Th (Mie)+ Exp, ext, transmittance \\
\hline Pustovalov et al. [33] & Water & $50,100,150$ & $250-2500$ & Th (Mie), absorption, scat \\
\hline Gorji et al. [43] & DI water & 20 & $250-1100$ & Th (Mie)+ Exp, ext, transmittance \\
\hline Astafyeva et al. [37] & Water & $20,50,100$ & $300-1000$ & Th (Mie)-abs., scat., ext, indicatr \\
\hline Holm et al. [38] & Water & $20-140$ & $300-1350$ & Th (Mie)-abs., scat., ext. \\
\hline \multirow[t]{2}{*}{ Chen et al. [39] } & Water & $20-100$ & $300-1200$ & Th (FDTD)-abs., scat., ext \\
\hline & $A l$ & & & \\
\hline Taylor et al. [40] & Water, Thermin. & 30 & $250-2500$ & Th (Rayl)+ Exp, ext \\
\hline Pustovalov et al. [30] & Water & $10-250$ & $250-1100$ & Th (Mie)-abs., scat., ext \\
\hline Saidur et al. [44] & Water & $1-20$ & $250-2500$ & Th (Rayl)-abs., scat., ext \\
\hline Zhu et al. [45] & Water & 130 & $300-900$ & Th (Mie)+ Exp, transmittance. \\
\hline Astafyeva et al. [37] & Water & $20,50,100$ & $300-1000$ & Th (Mie)-abs., scat., ext. \\
\hline Holm et al. [38] & Water & $20-140$ & $200-1250$ & Th (Mie)-abs., scat., ext. \\
\hline \multirow[t]{2}{*}{ Chen et al. [39] } & Water & $20-100$ & $300-1200$ & Th (FDTD)-abs., scat., ext \\
\hline & $\mathrm{Ni}$ & & & \\
\hline Kameya et al. [46] & Alkylnapht. Water & 4.9 & $400-10,000$ & Th (Mie)+ Exp, abs., transmittanc \\
\hline Pustovalov et al. [30] & Ionic liquid & $10-250$ & $250-1100$ & Th (Mie)-abs., scat., ext \\
\hline Zhang et al. [47] & Water & 40 & $250-2500$ & Th (Rayl)+ Exp, ext \\
\hline Pustovalov et al. [33] & Water & $50,100,150$ & $250-2500$ & Th (Mie), abs, sca \\
\hline \multirow[t]{2}{*}{ Astafyeva et al. 2017 [37] } & & $20,50,100$ & $300-1000$ & Th-abs., scat., ext, indicatrices \\
\hline & $\mathrm{Cu}$ & & & \\
\hline Taylor et al. [40] & Water, therminol & 30 & $250-2500$ & Th (Rayl)+ Exp, ext \\
\hline Dang et al. [48] & Water, PEG & $10-40$ & $450-800$ & Exp, absorbance \\
\hline Pustovalov et al. [30] & Water & $10-250$ & $250-1100$ & Th (Mie)-abs., scat., ext \\
\hline He et al. [49] & DI Water & 25,50 & $250-2500$ & Th + Exp, extinc, transmittance \\
\hline Zhang et al. [47] & Ionic liquid & 40 & $250-2500$ & Th, extinction \\
\hline Astafyeva et al. [37] & Water & $20,50,100$ & $300-1000$ & Th-abs., scat., ext, indicatrices. \\
\hline Holm et al. [38] & Water & $20-140$ & $300-1350$ & Th (Mie)-abs., scat., ext. \\
\hline \multirow[t]{2}{*}{ Chen et al. [39] } & Water & $20-100$ & $300-1200$ & Th (FDTD)-abs., scat., ext \\
\hline & Mo, Pt, Ti, Pd, Zn & & & \\
\hline Pustovalov et al. [33] & Water & $50,100,150$ & $250-2500$ & Th (Mie), absorption, scatt, \\
\hline Astafyeva et al. [50] & Water & $50,100,150$ & $250-2500$ & Th (Mie), abs., scat., ext. \\
\hline
\end{tabular}


Table 1 (continued)

\begin{tabular}{lllll}
\hline References & NP material, fluid & NP size, $d_{0}(\mathrm{~nm})$ & Spectral interval $(\mathrm{nm})$ & $\begin{array}{l}\text { Th-theory (method), Exp- } \\
\text { experiment, results }\end{array}$ \\
\hline Astafyeva et al. [46] & Water & $100,150,200$ & $300,560,1000$ & Th-indicatrices \\
\hline
\end{tabular}

abs absorption; sca scattering; ext extinction; Th theory; Exp experiment

\subsection{Optical properties of selected metallic nanoparticles for solar absorption applications}

Optical properties of selected metallic NPs are analyzed here for the purpose of their possible solar absorption applications. Optical properties of NPs are determined by efficiency factors of absorption $K_{\text {abs }}$ scattering $K_{\text {sca }}$ and extinction $K_{\text {ext }}=K_{\text {abs }}+K_{\text {sca }}$ [15] of radiation by an NP and parameter $P_{1}=K_{\mathrm{abs}} / K_{\mathrm{sca}}$, which describes the correlation between absorption and scattering of radiation by NP and characterizes the contribution of the absorption in the process of NP-radiation interaction [20]. The maximal absorption and minimal scattering of radiation by NP are realized if absorption factor $K_{\text {abs }}$ has own maximum and parameter $P_{1}$ should be greater (or much greater) than 1 , $P_{1}>1$ (or $P_{1} \gg 1$ ). It means that the maximal part of radiation will be absorbed by NP during the first act of photon interaction with NP. Moreover, the dependence of $K_{\mathrm{abs}}(\lambda)$ should be coordinated with the dependence of solar intensity $I_{s}(\lambda)$. These facts will allow us to achieve maximal efficiency of solar radiation absorption by NPs and their heating. In the opposite case, when $K_{\text {sca }}>K_{\text {abs }}$ and $P_{1}<1$, scattering of solar radiation by NP will dominated under absorption by NP and following multiple scattering by NPs will lead to redistribution of radiation intensity between NPs and surrounding medium and a significant decrease in NP heating. The variant with value $P_{1} \approx 1$ means approximately equal possibility for the use of a NP as absorber and scatterer simultaneously.

The investigation of optical properties of 12 metallic NPs has been conducted [30, 37]. Au, Ag, Pt, Ti, Zn, Ni, Mo and Pd NPs were chosen as possible agents for absorption of solar energy, and the results of comparative analysis of their optical properties [33] are presented here. These NPs are immersed in water, and all results for them are presented for the spectral interval 200-2500 nm, which contains approximately $99 \%$ of whole solar energy. The values of optical indexes of refraction and absorption of metals and surrounding water were used from $[51,52]$.

The dependencies of solar irradiance $I_{\mathrm{S}}(1)$, factor $K_{\mathrm{abs}}$ and parameter $P_{1}$ on the wavelength $\lambda$ in the spectral interval 200-2500 nm for mentioned spherical homogeneous metallic NPs with the values of NP radii $r_{0}=25,50$, $75 \mathrm{~nm}$ are presented in Figs. 2 and 3.

$\mathrm{Au}$ and Ag NPs are mostly investigated by different authors for solar thermal applications [29-43]. The dependencies of efficiency factor $K_{\mathrm{abs}}$ on $\lambda$ for Au and Ag NPs have typical plasmon resonance shapes with formation of one resonance maximum of $K_{\mathrm{abs}}^{\mathrm{max}}$ (Fig. 2). The factor $K_{\text {abs }}$ sharply decreases up to $\sim 10^{1}-10^{2}$ times in comparison with its maximum $K_{\mathrm{abs}}^{\max }$, and $\mathrm{Au}$ and Ag NPs practically have insignificant absorption of solar radiation in IR region. Suitable values of $P_{1} \geq 1$ are realized for Au NPs for whole spectral interval $200-2500 \mathrm{~nm}$ only for $r_{0}=25 \mathrm{~nm}$. It means a sharp increase in radiation scattering by Au NPs with the increase in NP radius $r_{0}$. For $\mathrm{Ag}$ NPs, the values of $P_{1} \geq 1$ are realized for the narrow intervals of wavelengths and for all presented values of $r_{0}$.

Au and Ag NPs were widely used in experiments [29, $31,32,34-36,40,42,43$ ]. Chen et al. [35] experimentally studied the size-dependent optical properties of aqueous Au nanofluids synthesized via the one-step method. According to Fig. 4, the Au nanofluid with nanoparticle size of $25 \mathrm{~nm}$ showed the best absorbance characteristic compared to 33-nm- and 40-nm-sized particles since the 25-nm sample had the highest absorbance in the peak spectra intensity of solar radiation. These experimental results support the theoretical calculations in Fig. 2a for Au NPs. On the other hand, Au and Ag NPs do not show their real applicability for effective absorption of solar radiation, and therefore, they are not suitable for this purpose.

The dependencies of $K_{\text {abs }}$ on $\lambda$ for fixed values of $r_{0}$ have typical plasmon resonance shapes for all presented metallic NPs (Figs. 2, 3). An increase in $r_{0}$ leads to the formation following plasmon resonances -1 (for Ti, Ni NPs) and 2 (for $\mathrm{Pt}, \mathrm{Mo}, \mathrm{Pd}$ NPs) resonances for $r_{0}=50 \mathrm{~nm}$ and the formation of 2 (for Pt, Ti, Ni, Pd NPs) and 3 (for Mo NP) resonances for $r_{0}=75 \mathrm{~nm}$. Some oscillation structures of the dependencies of $K_{\mathrm{abs}}$ on $\lambda$ are formed with increasing $r_{0}$ for Zn NPs.

The significant decrease in $K_{\mathrm{abs}}$ is realized in the UV and IR spectral intervals, respectively, with the decrease and increase in $\lambda$ accordingly. The increase in $r_{0}$ leads to the shifting of the placement of maximum $K_{\mathrm{abs}}^{\max }$ to bigger values of $\lambda$ in VIS and IR regions and leads to a decrease in its value. It means the possibility to match the dependence of $K_{\mathrm{abs}}(\lambda)$ to the dependence $I_{s}(\lambda)$ up to near close or practically overlapping of these ones. So, the absorption spectrum of metallic NPs is typically broadened with increasing $r_{0}$ and an NP can absorb a larger portion of the spectrum maintaining an absorption peak and leading to a further enhancement in the absorption efficiency. 
Fig. 2 Dependencies of solar irradiance $I_{\mathrm{S}}(\mathbf{a}, \mathbf{c}, \mathbf{e}, \mathbf{g}$ solid, orange, left axis), absorption efficiency factor $K_{\text {abs }}$ of NP (a, c, $\mathbf{e}, \mathbf{g}$ right axis) and parameter $P_{1}(\mathbf{b}, \mathbf{d}, \mathbf{f}, \mathbf{h})$ on $\lambda$ for $A u(\mathbf{a}, \mathbf{b})$, Pt (c, d), Ag (e, f), Pd (g, h) NPs with the radii $r_{0}=25$ (dotted, green), 50 (dashed, violet), 75 (dashed-dotted, red) $\mathrm{nm}$. Horizontal solid line denotes the value $P_{1}=1$ [33]
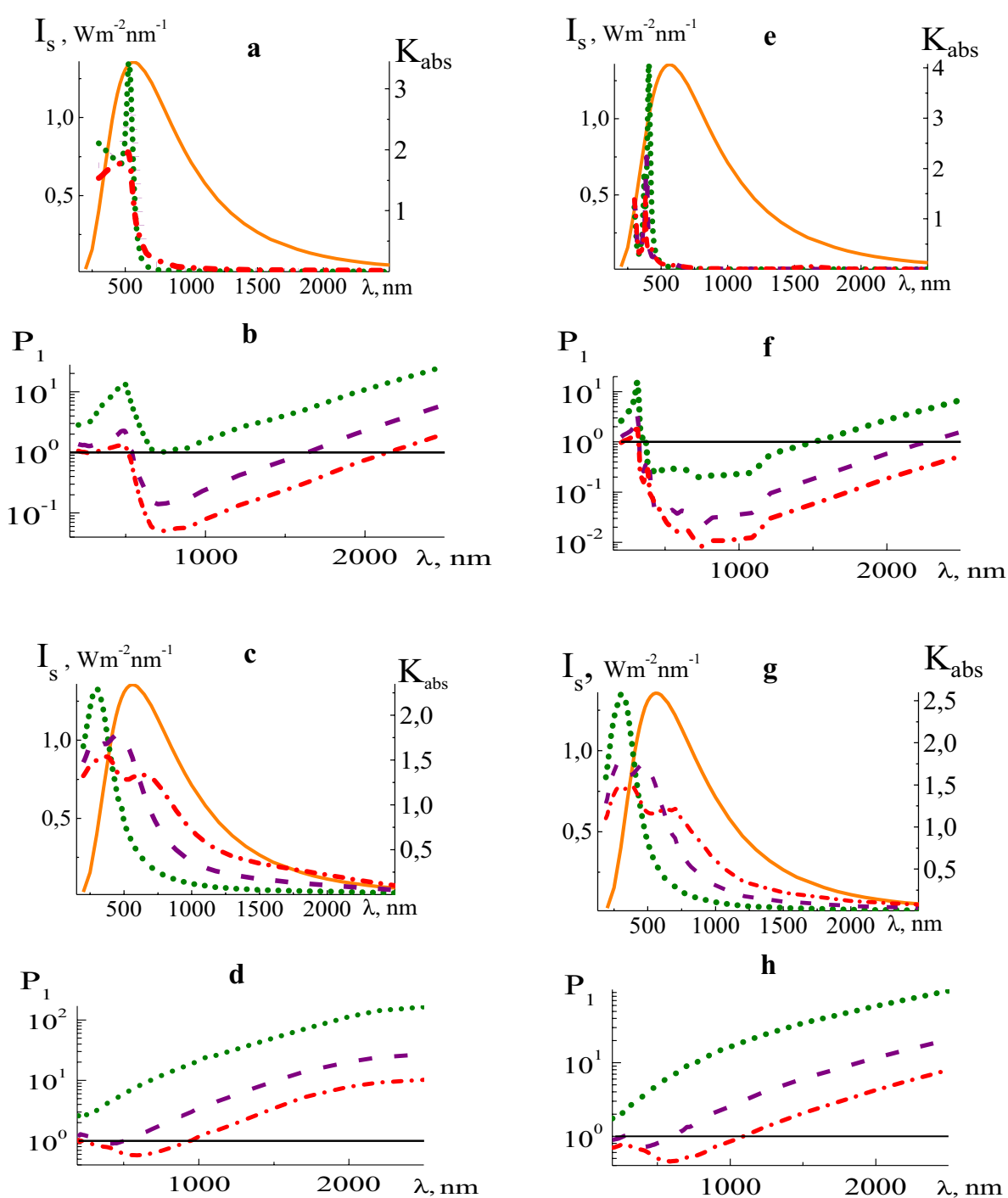

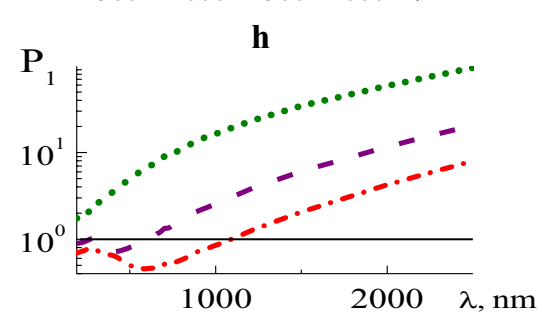

Main feature of all presented dependencies of $P_{1}\left(\lambda, r_{0}\right)$ is the decrease in $P_{1}$ with increasing $r_{0}$ for the whole spectral interval $200-2500 \mathrm{~nm}$. It is interesting to note the values of $P_{1} \geq 10-100$ for mentioned NPs with $r_{0}=25-75 \mathrm{~nm}$ in IR spectral interval. However, the value of $P_{1}$ with increasing $r_{0}$ can be smaller than 1 in some regions of solar spectrum or practically in whole solar spectrum.

On the other hand, the parameters $P_{1}$ for Ti and Ni NPs are bigger than $1, P_{1}>1$, for $r_{0}=25,50,75 \mathrm{~nm}$ for whole spectral interval $250-2500 \mathrm{~nm}$. It means that Ti, Ni NPs are good absorbers of radiation in a wide range of UV, VIS and IR optical spectrum in comparison with other presented NPs.

In part 2, the results of the investigations [29-49] have been reviewed. Comprehensive analysis of optical properties of eight metallic NPs with different radii in near-UV, VIS and IR radiation intervals has been carried out on the basis of the choice of the NP metal, radius $r_{0}$ and factor $K_{a b s}(\lambda)$ and coordination between the dependencies of factor of radiation absorption $K_{\mathrm{abs}}(\lambda)$ by NP and solar irradiance $I_{S}(\lambda)$ and estimations of novel parameter $P_{1}$ with condition $P_{1} \geq 1$ for effective absorption of solar radiation. Metallic Ti, Ni NPs can be applied as perspective candidates for effective absorption of solar radiation.

\section{Optical properties of homogeneous and core-shell nanoparticles}

\subsection{Analysis of optical properties of core-shell and homogeneous oxide nanoparticles}

Recently, many research efforts have been focused on the investigation of spherical core-shell NPs because of their unique size-dependent physical and chemical properties [12-14, 20, 21, 53-72]. Core-shell NPs have great potential 
Fig. 3 Dependencies of solar irradiance $I_{\mathrm{S}}(\mathbf{a}, \mathbf{c}, \mathbf{e}, \mathbf{g}$ solid, orange, left axis), absorption efficiency factor $K_{\text {abs }}$ of NP (a, c, $\mathbf{e}, \mathbf{g}$ right axis) and parameter $P_{1}(\mathbf{b}, \mathbf{d}, \mathbf{f}, \mathbf{h})$ on $\lambda$ for $Z n(\mathbf{a}, \mathbf{b})$, $\mathrm{Ni}(\mathbf{c}, \mathbf{d}), \mathrm{Mo}(\mathbf{e}, \mathbf{f}), \mathrm{Ti}(\mathbf{g}, \mathbf{h}) \mathrm{NPs}$ with the radii $r_{0}=25$ (dotted, green), 50 (dashed, violet), 75 (dashed-dotted, red) $\mathrm{nm}$. Horizontal solid line (black) denotes the value $P_{1}=1$ [33]
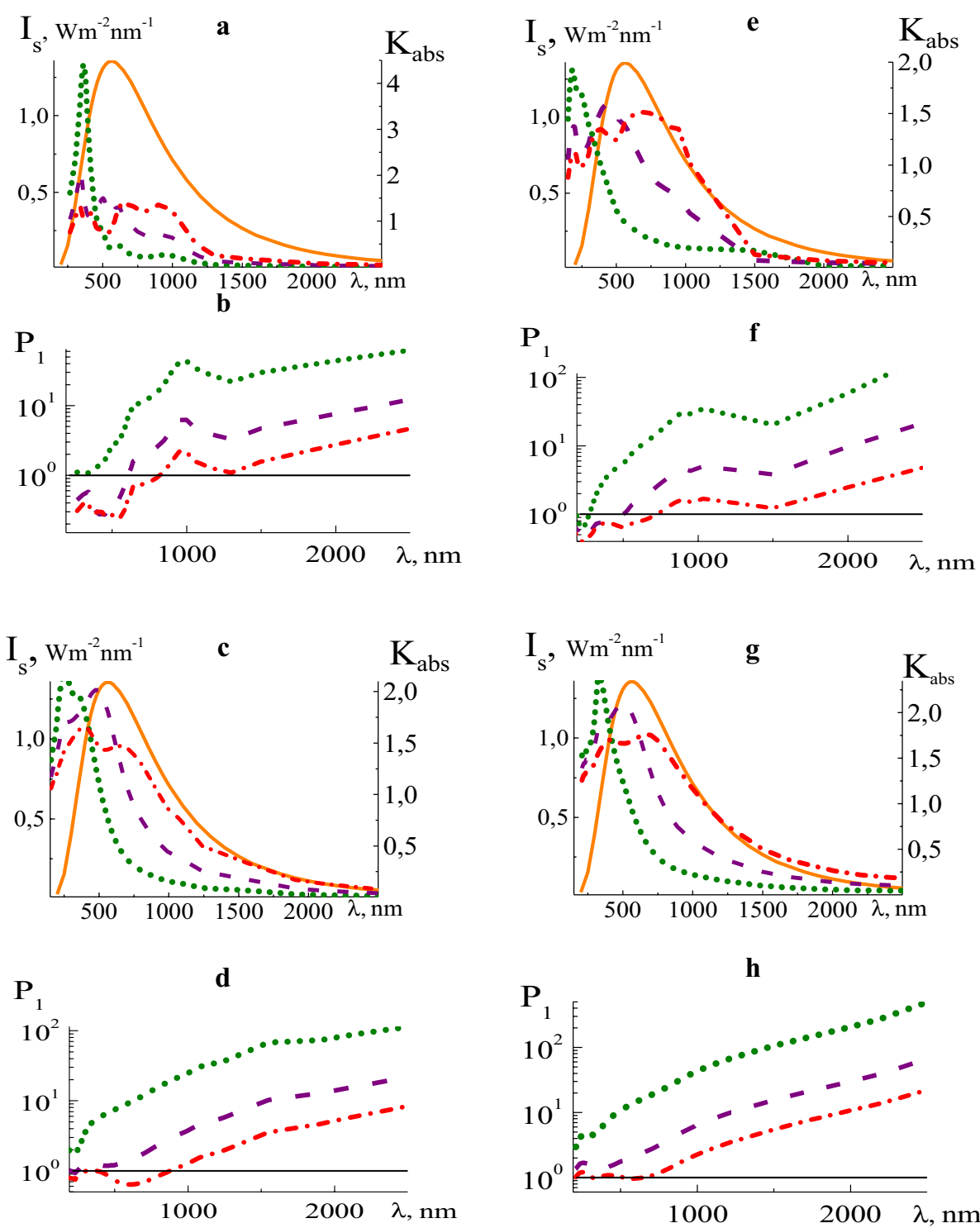

h

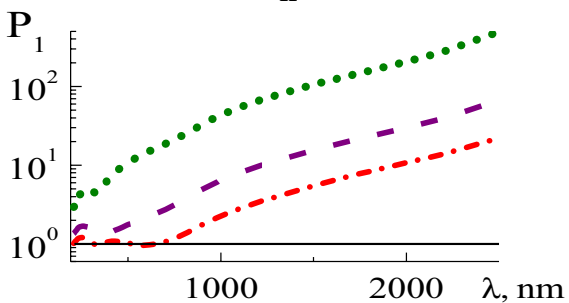

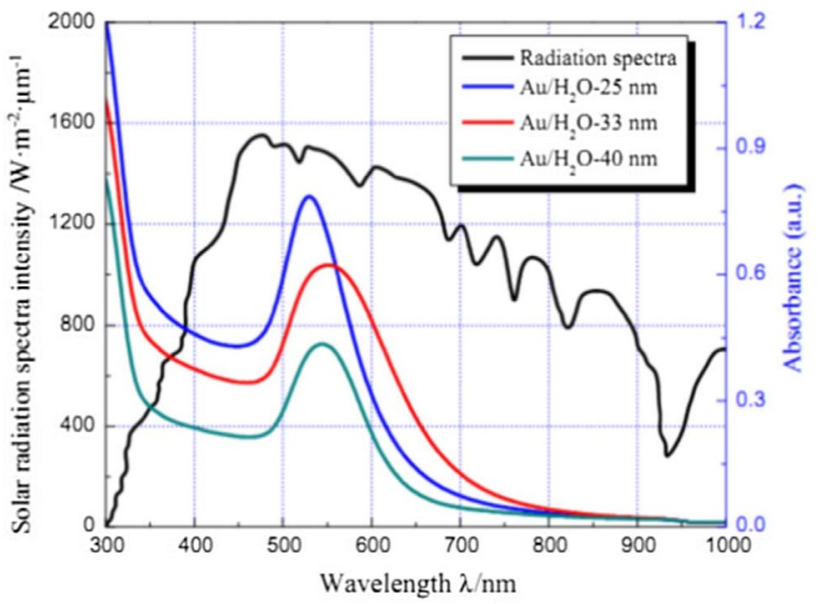

Fig. 4 Absorbance spectra of Au nanofluids with different nanoparticle sizes and solar radiation spectrum [35] for various applications due to strongly enhanced surface plasmon resonance for absorption and tuning of absorption and scattering bands across the VIS and near-IR intervals of the optical spectrum by varying the core and shell materials (metals, oxides, semiconductors), their composition and the relative core size and shell thickness (see Table 2).

Optical properties of material core and $\mathrm{Au}$ shell were investigated [53-60]. $\mathrm{SiO}_{2}, \mathrm{Fe}_{3} \mathrm{O}_{4}$ [53], $\mathrm{SiO}_{2}$ [54], $\mathrm{Fe}_{3} \mathrm{O}_{4}$ [55], $\mathrm{Si}, \mathrm{SiC}[56,57], \mathrm{Ag}[58,59], \mathrm{SiO}_{2}, \mathrm{ZrO}_{2}, \mathrm{TiO}_{2}[60]$ were used as core materials. Their results show next features and possibilities of the core-shell NPs use.

Increasing core size leads to shifting of the location of resonance wavelength and maximal values of optical factors to the larger values of wavelengths and decreasing their maxima [53]. It was found that plasmon resonance frequency can be precisely tuned by adjusting the Au layer 
Table 2 Optical properties of core-shell NPs

\begin{tabular}{|c|c|c|c|c|c|}
\hline Authors, year, reference & Core-shell/fluid & $r_{0}(\mathrm{~nm})$ & $\Delta r_{1}(\mathrm{~nm})$ & $\Delta \lambda(\mathrm{nm})$ & $\begin{array}{l}\text { Th-theory (method), Exp- } \\
\text { experiment, results }\end{array}$ \\
\hline Bardhan et al. [53] & $\mathrm{SiO}_{2}-\mathrm{Au} /$ water & $30,40,60$ & 12 & $400-1200$ & Th (Mie)+ Exp, abs., scat., ext \\
\hline Lee et al. [54] & $\mathrm{SiO}_{2}-\mathrm{Au} /$ water, EG & $20-55$ & $3-10$ & $200-2000$ & Th (Mie)+ Exp, abs., scat. \\
\hline Bardhan et al. [53] & $\mathrm{Fe}_{3} \mathrm{O}_{4}-\mathrm{Au} /$ water & $30,40,60$ & 12 & $400-1250$ & Th + Exp, abs., scat., ext. \\
\hline Ghazanfari et al. [55] & $\mathrm{Fe}_{3} \mathrm{O}_{4}-\mathrm{Au} /$ water & 9.5 & 6 & $450-750$ & Th + Exp (DLS), absorbance \\
\hline Lv et al. [56] & $\mathrm{Si}-\mathrm{Au}, \mathrm{Ag}, \mathrm{Al}, \mathrm{Cu} /$ water & $6-25$ & $2-8$ & $350-3000$ & Th (Drude)-extinction \\
\hline Wu et al. [57] & $\mathrm{Si}-\mathrm{Au}, \mathrm{Ag}, \mathrm{Al}, \mathrm{Cu} /$ water & 42,82 & $0-82$ & $250-2500$ & Th (Mie)-absorption, ext \\
\hline Pustovalov et al. [58] & $\mathrm{Au}-\mathrm{Ag}, \mathrm{Ag}-\mathrm{Au} /$ water & $5-60$ & $5,20,40$ & $300-650$ & Th (Mie)-absorption, extinction \\
\hline Byers et al. [59] & $\mathrm{Au}-\mathrm{Ag} /$ Water & 22.5 & 5 & $1450-2100$ & Exp-scattering \\
\hline Laaksonen et al. [60] & $\begin{array}{l}\mathrm{Au}, \mathrm{Ag}, \mathrm{Cu}-\mathrm{SiO}_{2}, \mathrm{TiO}_{2}, \mathrm{ZrO}_{2} / \\
\text { water }\end{array}$ & $5-100$ & $0-100$ & $300-800$ & Th (Mie)-absorption, ext. \\
\hline Ruffino et al. [61] & $\begin{array}{l}\mathrm{Ag}-\mathrm{Ag}_{2} \mathrm{O}, \mathrm{Pd}-\mathrm{PdO}, \mathrm{Al}-\mathrm{Al}_{2} \mathrm{O}_{3}, \mathrm{Cu}- \\
\mathrm{Cu}_{2} \mathrm{O}, \mathrm{Ti}-\mathrm{TiO}_{2} / \text { water }\end{array}$ & $30,50,70,90,110$ & $0-80$ & 550 & $\begin{array}{l}\text { Indicatrices of scattering radiation } \\
\text { by NP }\end{array}$ \\
\hline Menbari et al. [62] & $\begin{array}{l}\mathrm{CuO}+\mathrm{Al}_{2} \mathrm{O}_{3} \text {, binary mixture/ } \\
\text { Water }+\mathrm{EG}\end{array}$ & $\begin{array}{l}\mathrm{CuO} \leq 100 \\
\mathrm{Al}_{2} \mathrm{O}_{3}=40\end{array}$ & - & $200-800$ & Th + Exp, ext. \\
\hline Pustovalov et al. [64] & $\mathrm{Zn}-\mathrm{ZnO}, \mathrm{Al}-\mathrm{Al}_{2} \mathrm{O}_{3} /$ water & $\begin{array}{l}5-45 \\
10-50\end{array}$ & 5 & $200-1000$ & $\begin{array}{l}\text { Th (Mie)-absorption, scattering, } \\
\text { extinction }\end{array}$ \\
\hline Astafyeva et al. [50] & Ti-TiO2, Ni-NiO, Zn-ZnO/water. & $40,65,90$ & 10 & $300,560,1000$ & $\begin{array}{l}\text { Indicatrices of scattering radiation } \\
\text { by NP }\end{array}$ \\
\hline Pustovalov [65] & $\begin{array}{l}\mathrm{Ni}-\mathrm{NiO}, \mathrm{Ti}-\mathrm{TiO}_{2}, \mathrm{Mo}-\mathrm{Mo}_{2} \mathrm{O}_{3} / \\
\quad \text { water }\end{array}$ & $40,65,90$ & 10 & $200-2500$ & $\begin{array}{l}\text { Th (Mie)-abs., scat., ext. factors } \\
\text { of NPs }\end{array}$ \\
\hline Pustovalov et al. [66] & $\mathrm{Ni}-\mathrm{NiO}, \mathrm{Ti}-\mathrm{TiO}_{2} /$ water & $40,65,90$ & 10 & $200-2500$ & Th (Mie) abs., scat. coeff. NPs \\
\hline Pustovalov et al. [67] & $\mathrm{Ni}-\mathrm{NiO}, \mathrm{Ti}-\mathrm{TiO}_{2} /$ water & $40,65,90$ & 10 & $200-2500$ & Th (Mie)-ext. coeff. of NPs and NFs \\
\hline
\end{tabular}

abs absorption; sca scattering; ext extinction; Th theory; Exp experiment

thickness which allows us to control the absorption peak of the NF and to match with the incident solar spectrum [54]. It was estimated a redshift in the plasmon resonance peak up to hundreds or even close to $1000 \mathrm{~nm}$ to a more desirable NIR wavelengths [60] and from a wavelength of about $600 \mathrm{~nm}$ to around $1400 \mathrm{~nm}$ for core-shell NPs [56].

Optical properties of core-shell NPs were experimentally assessed using UV-VIS spectrophotometer and dynamic light scattering [55]. Simulation results based on extended Mie theory show the nonlinear dependencies of optical properties of core-shell silver-gold (and gold-silver) NPs on radiation wavelengths, core radii and shell thicknesses [58, 59]. It should be noted the theoretical [56] and experimental [57] investigations of optical properties of core-shell NPs with $\mathrm{Si}, \mathrm{SiC}$ core and $\mathrm{Ag}, \mathrm{Cu}$, Al shell.

The metal core-its oxide shell NPs are very interesting for the improvement in and manipulation of the NP plasmon resonances. The formation of thin oxide shell with the thicknesses of about 5-10 nm on metallic NP can be achieved by different chemical [11] and physical [63] methods, as a result of natural oxidation of metal NPs in reactive ambience. The action of intensive optical (solar) radiation and following NP heating can promote the oxidation of surface layer of metallic NP and the formation of hybrid metallic core- its oxide shell NPs.
Zhang et al. [47] experimentally and theoretically investigated radiation properties of the ionic fluid and its NFs. It was experimentally found that optical absorption property of liquid can be significantly enhanced by dispersing a very low volume fraction of NPs in it. At the volume fraction of $10 \mathrm{ppm}$, the extinction coefficient of the NF containing the $\mathrm{Ni}$ NPs with an average size of $40 \mathrm{~nm}$ is higher than that of the one containing the Cu NPs with the similar average size, owing to their different complex refractive indexes. The extinction coefficients of ionic liquid NFs containing $\mathrm{Ni}, \mathrm{Cu}$ and carbon-coated $\mathrm{Ni}(\mathrm{C} / \mathrm{Ni}) \mathrm{NPs}$ were modeled based on Rayleigh approximation. Figure 5 shows that in the wavelength below $1200 \mathrm{~nm}$, the model fails to accurately predict the extinction coefficients, especially for $\mathrm{Cu}$ and Ni NPs. This discrepancy has been explained due to possible surface oxidation of the metal NPs and changing optical and other properties of NPs. This fact has been also established in experimental investigation with metallic NPs [40]. The possibility of the formation of oxide shell on the metal NP surface should be taken into account for possible solar thermal applications of metallic NPs.

Optical properties (efficiency factors of absorption, scattering and extinction) of core-shell NPs with metallic core and its oxide shell $\left(\mathrm{Ag}-\mathrm{Ag}_{2} \mathrm{O}, \mathrm{Al}-\mathrm{Al}_{2} \mathrm{O}_{3}, \mathrm{Cu}-\mathrm{Cu}_{2} \mathrm{O}\right.$, etc.) [60] and $\left(\mathrm{Ni}-\mathrm{NiO}, \mathrm{Ti}-\mathrm{TiO}_{2}, \mathrm{Zn}-\mathrm{ZnO}, \mathrm{Mo}-\mathrm{Mo}_{2} \mathrm{O}_{3}\right)[66,67]$ have 


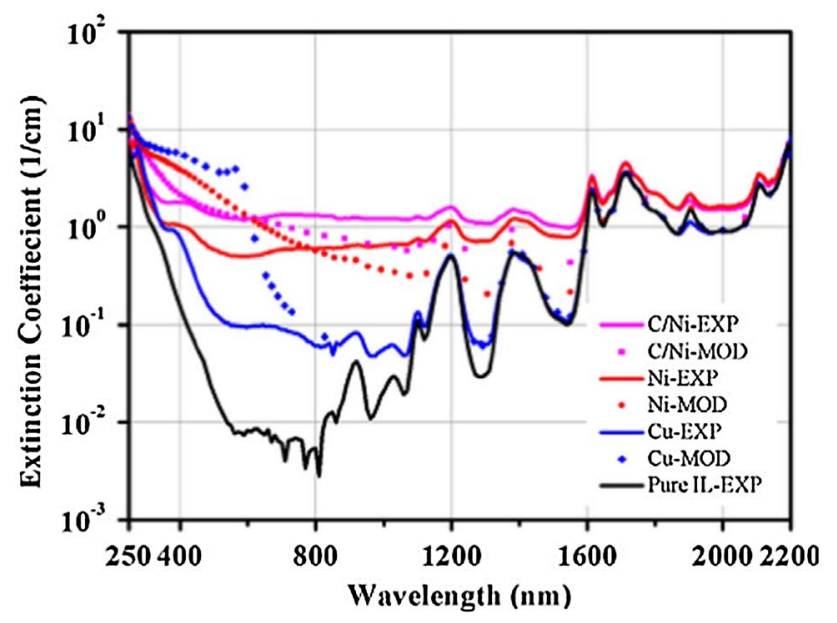

Fig. 5 Rayleigh scattering approximation of ionic nanofluids extinction coefficients with average sizes of $40 \mathrm{~nm}$ at volume fraction of $10 \mathrm{ppm}$ [47]

been numerically calculated on the basis of Mie theory for the purposes of solar radiation absorption. These results highlight the possibility of single core-shell $\mathrm{Ti}_{-} \mathrm{TiO}_{2}$ and $\mathrm{Ni}-\mathrm{NiO} \mathrm{NPs}$ with radii of about $75-100 \mathrm{~nm}$ for effective application as perfect absorbers for solar radiation in the complete optical spectrum 200-2500 nm [64-67]. The angle-dependent light scattering indicatrices and scattering efficiency for core-shell NPs are discussed as a function of the core radius-and-shell thickness ratio and on their relative comparison [50,61].

Synthesis, optical and plasmonic properties of core-hollow and material-shell NPs were investigated $[68,69]$. Dependencies of optical properties of spherical two-layered NPs on parameters of gold core and some material shell are investigated [70]. Optical properties of $\mathrm{Ag} @ \mathrm{TiO}_{2}$ and $\mathrm{CdS} @ \mathrm{TiO}_{2}$ core-shell nanostructures were investigated [71]. The implementation of single-particle absorption spectroscopy on strongly scattering plasmonic NPs has been presented [72].

Homogeneous oxide $\left(\mathrm{Al}_{2} \mathrm{O}_{3}, \mathrm{SiO}_{2}, \mathrm{CuO}, \mathrm{ZnO}\right.$, etc.) NPs were used in experimental and theoretical investigations of solar radiation absorption by NPs (see Table 3 ) $[43,50$, $65,67,73-80]$.

Optical properties of titania $\left(\mathrm{TiO}_{2}\right)$ and alumina $\left(\mathrm{Al}_{2} \mathrm{O}_{3}\right)$ water-based NFs were investigated experimentally and theoretically in the spectral range $250-1100 \mathrm{~nm}$ [73]. It was supposed that titania NP may perform as a good solar irradiation absorber if it can be stabilized properly. Optical absorption measurements limited to 200-1300 nm were performed on several water-based $\mathrm{NFs}\left(\mathrm{Al}_{2} \mathrm{O}_{3}, \mathrm{CuO}\right.$, $\mathrm{TiO}_{2}, \mathrm{ZnO}, \mathrm{CeO}_{2}$ and $\mathrm{Fe}_{2} \mathrm{O}_{3}$ ) [74]. Experimental extinction coefficient in the spectral interval $250-1100 \mathrm{~nm}$ for magnetite $\mathrm{NF} \mathrm{Fe}_{3} \mathrm{O}_{4}$ with NP sizes $15 \mathrm{~nm}$ was larger than the calculated values [43]. Optical properties of water-based NFs from MgO NPs with sizes $10 \mathrm{~nm}$ were investigated in the spectral interval $300-1500 \mathrm{~nm}$ [80]. The investigation of optical properties and radiation transfer of $\mathrm{TiO}_{2} \mathrm{NFs}_{\text {sith }}$ the consideration of scattering effects has been carried out [81].

NPs in NF have a great tendency to aggregate into large secondary agglomerate, due to their nanoscale size and high surface energy, even in the presence of the antiagglomeration agent. Aggregation process and its effect on optical characteristics of the $\mathrm{Al}_{2} \mathrm{O}_{3} \mathrm{NFs}$ were investigated using electron microscopy, dynamic light scattering and UV-VIS spectroscopy, and the results indicate that extinction coefficients of the NFs reduce rapidly with time within visible to near-IR region [75-77]. The effects of dispersants, mass fractions and NP materials on the radiation properties of NFs are analyzed [78]. The optical properties of CuO NF were investigated at the different temperatures [79].

The advantage of the applications of oxide NPs in thermal processes consists in their permanent properties during long time. On the other hand, the radiation absorption, scattering and extinction of homogeneous oxide $\mathrm{TiO}_{2}, \mathrm{NiO}$ and $\mathrm{Mo}_{2} \mathrm{O}_{3} \mathrm{NPs}$ have been investigated $[65,67]$. These NPs have significant absorption only in the spectral interval $300-500 \mathrm{~nm}$ and show practical impossibility to use oxide $\mathrm{TiO}_{2}, \mathrm{NiO}$ and $\mathrm{Mo}_{2} \mathrm{O}_{3} \mathrm{NPs}$ for effective absorption of solar radiation in spectral interval $500-2500 \mathrm{~nm}$ containing $75 \%$ of solar energy. These results are in contradiction with results [73], and they are discussed more widely in the next part.

\subsection{Optical properties of selected homogeneous metallic, oxide and metallic core and its oxide shell nanoparticles}

It is very interesting to compare the optical properties of homogeneous metallic, oxide and metallic core- its oxide shell NPs for solar radiation absorption. The matter is that preceding theoretical and experimental investigations [29-81] did not reply on main question because of some contradictive results and conclusions what types of NPs from mentioned above can be used more properly for absorption of solar radiation. As it was mentioned before, optical properties of Ti, Ni NPs could be selected for achievement of maximal absorption of solar energy by NPs. On the other hand, it was established that oxide shell can be formed on the metallic NPs and with time flow the thickness of oxide shell can be significant and homogeneous oxide NP can be arisen from metallic NP.

That is why metallic $\mathrm{Ti}$, Ni NPs, oxide $\mathrm{TiO}_{2}$, NiO NPs and metal core and oxide shell $\mathrm{Ti}_{-} \mathrm{TiO}_{2}, \mathrm{Ni}-\mathrm{NiO} \mathrm{NPs}$ were chosen for the following analysis for solar absorption 
Table 3 Optical properties of homogeneous oxide NPs

\begin{tabular}{|c|c|c|c|c|}
\hline Authors, year, reference & NP material, fluid & NP size, $d_{0}(\mathrm{~nm})$ & Spectral interval (nm) & $\begin{array}{l}\text { Th-theory (method), Exp- } \\
\text { experiment, results }\end{array}$ \\
\hline & $\mathrm{TiO}_{2}$ & & & \\
\hline Said et al. [73] & Water & $21(14-38)$ & $250-1100$ & Th (Rayl)+ Exp, abs., scatt, extinc. \\
\hline Pustovalovl [67] & Water & $100,150,250$ & $200-2500$ & Th (Mie), absorption, scatt, ext. \\
\hline Milanese et al. [74] & Water & 50 & $250-1300$ & Exp. ext., trans. \\
\hline \multirow[t]{2}{*}{ Jianyu et al. [81] } & Water & $20-600$ & $300-800$ & Th+Exp. \\
\hline & $\mathrm{Al}_{2} \mathrm{O}_{3}$ & & & \\
\hline Said et al. [73] & Water & 13 & $250-1100$ & Th + Exp, abs., scat, ext. \\
\hline Sajid et al. [75] & Water & $1,10,20$ & $200-1000$ & $\operatorname{Exp}(T E M)+T h-a b s .$, scat, ext. \\
\hline Sajid et al. [76] & Water & 13 & $200-750$ & Th (Rayl)+ Exp—abs., sca. \\
\hline Song et al. [77] & Water, ethyl & $1-50$ & $250-900$ & Th(Mie)+ Exp, abs., scat, extinct \\
\hline \multirow[t]{2}{*}{ Milanese et al. [74] } & Water & $40-50$ & $250-1300$ & Exp. extinction, transmittance \\
\hline & $\mathrm{ZnO}$ & & & \\
\hline Zhu et al. [78] & Water & $10-100$ & $300-2500$ & Th + Exp, abs., transmit. \\
\hline \multirow[t]{2}{*}{ Milanese et al. [74] } & Water & 70 & $250-1300$ & Exp. extinction, transmittance \\
\hline & $\mathrm{Fe}_{3} \mathrm{O}_{4}$ & & & \\
\hline \multirow[t]{2}{*}{ Gorji et al. [43] } & Water & 15 & $200-1100$ & Th + Exp, extinction, transmit. \\
\hline & $\mathrm{CuO}$ & & & \\
\hline \multirow[t]{2}{*}{ Karami et al. [79] } & Water + EG & $10-100$ & $200-2500$ & Th + Exp \\
\hline & $\mathrm{CuO}, \mathrm{CeO}_{2}, \mathrm{Fe}_{2} \mathrm{O}_{3}$ & & & \\
\hline \multirow[t]{2}{*}{ Milanese et al. [74] } & Water & $10-100$ & $250-1300$ & Exp. extinction, transmittance \\
\hline & $\mathrm{NiO}, \mathrm{Mo}_{2} \mathrm{O}_{3}$ & & & \\
\hline \multirow[t]{2}{*}{ Pustovalov et al. [65] } & Water & $100,150,250$ & $200-2500$ & Th(Mie)-absorption, scat., ext. \\
\hline & $\mathrm{MgO}$ & & & \\
\hline \multirow[t]{2}{*}{ Kasejan et al. [80] } & Water & 10 & $300-1500$ & Th-extinction, transmittance \\
\hline & $\mathrm{TiO}_{2}, \mathrm{NiO}$ & & & \\
\hline Astafyeva et al. [50] & Water & $100,150,250$ & $300,560,1000$ & Th-indicatrices \\
\hline
\end{tabular}

abs absorption; sca scattering; ext extinction; Th theory; Exp experiment

applications on the basis of comparison of optical properties of various NPs in preceding parts.

Figures 6 and 7 present the dependencies of solar irradiance $I_{\mathrm{S}}$, absorption efficiency factor $K_{\mathrm{abs}}$ and parameter $\mathrm{P}_{1}$ for homogeneous $\mathrm{Ti}_{1} \mathrm{TiO}_{2}$, core-shell Ti-TiO ${ }_{2} \mathrm{NPs}$ and accordingly $\mathrm{Ni}, \mathrm{NiO}, \mathrm{Ni}-\mathrm{NiO}$ NPs with the radii $r_{0}, r_{1}=50$, $75,100,125 \mathrm{~nm}$ (the thickness of oxide shell is $\Delta r_{1}=10 \mathrm{~nm}$, $r_{1}=r_{0}+\Delta r_{1}, r_{0}$-core radius) on $\lambda$ [65]. The radii of homogeneous NPs $r_{0}$ are equal to the radii $r_{1}=r_{0}+\Delta r_{1}$ of core-shell NPs according to the correct comparison of the results for equivolume NPs. It was used refractive indices $[82,83]$ for oxides.

The dependencies of $K_{\text {abs }}(\lambda)$ for $\mathrm{Ti}, \mathrm{Ti}-\mathrm{TiO}_{2}$ and $\mathrm{Ni}, \mathrm{Ni}-\mathrm{NiO}$ NPs with $r_{0}, r_{1}=75 \mathrm{~nm}$ are very close to the dependence of $I_{S}(\lambda)$ in whole spectral interval. The dependencies of $K_{\text {abs }}$ on $\lambda$ have been shifted to smaller values of wavelength for $r_{0}$, $r_{1}=50 \mathrm{~nm}$, and they have been shifted to larger values of wavelength for $r_{0}, r_{1}=100,125 \mathrm{~nm}$ in comparison with the location of $I_{\mathrm{S}}(\lambda)$ for $r_{0}, r_{1}=75 \mathrm{~nm}$.
The parameter $P_{1}$ is larger than $1, P_{1} \geq 1$, in whole spectrum for Ti NPs with $r_{0}=50,75 \mathrm{~nm}$ but for Ni NPs only for $r_{0}=50 \mathrm{~nm}$. The increase in $r_{0}$ leads to the formation of wavelength region, where $P_{1}$ is smaller than 1 in some spectral intervals (see Figs. 6,7 ). The value of $P_{1}$ is sharply increased up to $P_{1} \sim 10-20$ with increasing $\lambda$ in the deep infrared spectral interval. But the influence of this fact is decreased due to small part of solar energy concentrated in this spectral interval.

The presence of an oxide shell leads to an increase in absorption compared to scattering of radiation by twolayered $\mathrm{Ti}_{-}-\mathrm{TiO}_{2}, \mathrm{Ni}-\mathrm{NiO} \mathrm{NPs}$ in comparison with pure $\mathrm{Ti}$, Ni NPs in the important spectral intervals 250-1000 nm and improves the possibility of $\mathrm{Ti}_{-} \mathrm{TiO}_{2}, \mathrm{Ni}-\mathrm{NiO} \mathrm{NPs}$ applications with enhanced performance for energy absorption. The parameter is equal to $P_{1} \geq 1$ in whole interval 200-2500 nm for Ti-TiO 2 NPs with $r_{1} \leq 100 \mathrm{~nm}$ and for $\mathrm{Ni}-\mathrm{NiO}$ NPs with $r_{1} \leq 75 \mathrm{~nm}$.

The $\mathrm{TiO}_{2}$ and NiO NPs have significant absorption only in the spectral interval 300-500 nm, and their values of $K_{\mathrm{abs}}$ 
Fig. 6 Dependencies of absorption factor $K_{\mathrm{abs}}$ and parameter $P_{1}$ of homogeneous $\mathrm{Ti}(\mathbf{a}, \mathbf{b}), \mathrm{TiO}_{2}(\mathbf{e}, \mathbf{f}) \mathrm{NPs}$ and for core-shell $\mathrm{Ti}+\mathrm{TiO}_{2}(\mathbf{c}, \mathbf{d})$, $\Delta r_{1}=10 \mathrm{~nm}$, NPs with $r_{0}, r_{1}=50$ (dashed, blue), 75 (dasheddotted, red), 100 (dotted, green), 125 (solid, brown) nm (all curves are referred to right axis) and solar irradiance $I_{\mathrm{S}}(1$, solid, orange, $\mathbf{a}-\mathbf{f}$ all curves are referred to left axis) on wavelength $\lambda$. Horizontal solid line (black) denotes the value $P_{1}=1[65]$
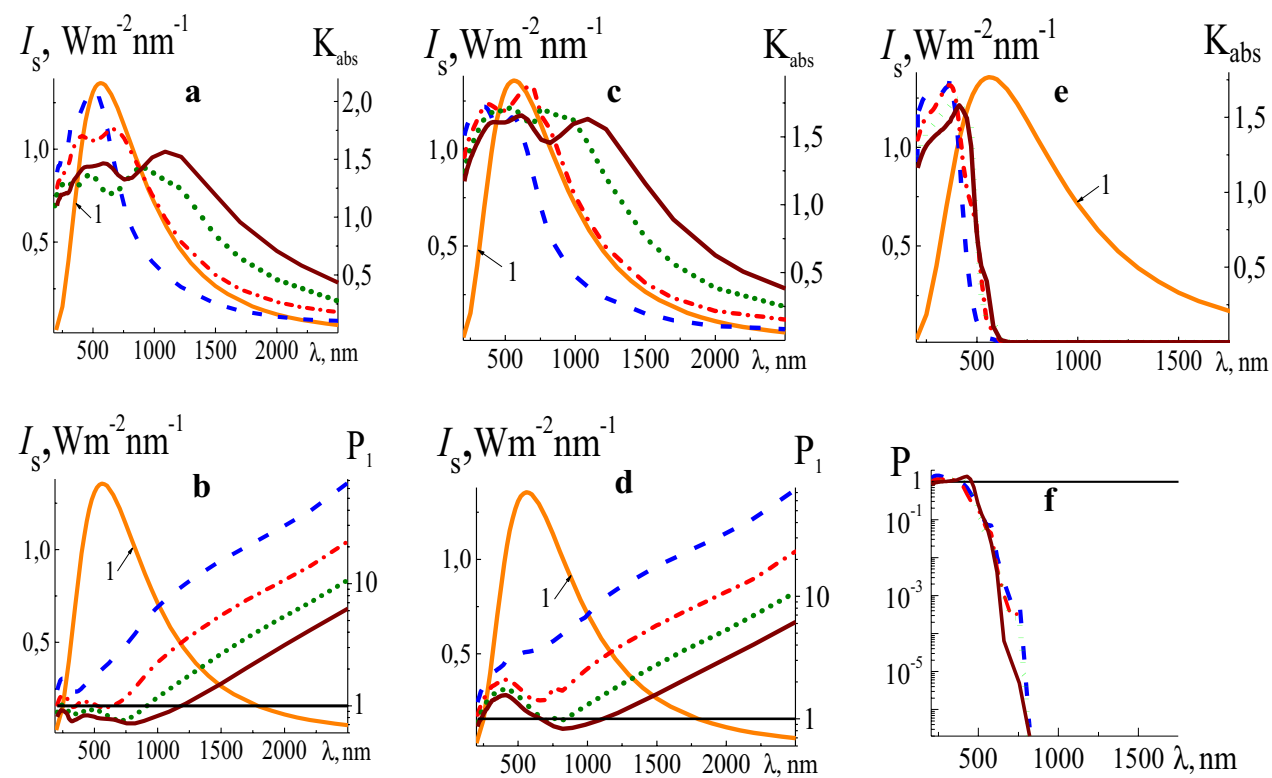
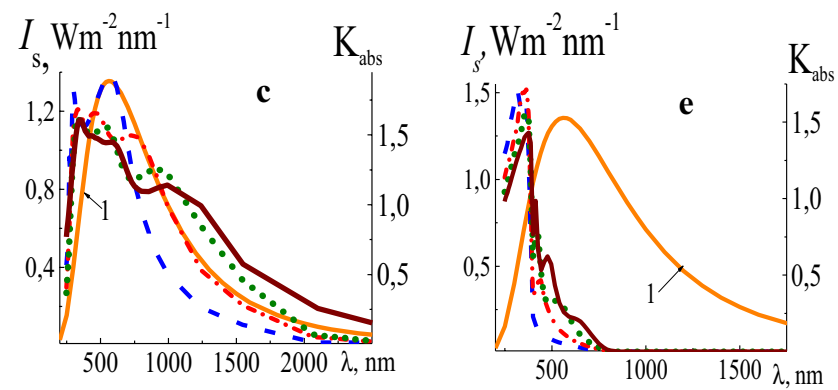

Fig. 7 Dependencies of absorption factor $K_{\text {abs }}$ and parameter $P_{1}$ of homogeneous $\mathrm{Ni}(\mathbf{a}, \mathbf{b}), \mathrm{NiO}(\mathbf{e}, \mathbf{f}) \mathrm{NPs}$ and for core-shell Ni-NiO (c, d), $\Delta r_{1}=10 \mathrm{~nm}$, NPs with $r_{0}, r_{1}=50$ (dashed, blue), 75 (dasheddotted, red), 100 (dotted, green), 125 (solid, brown) nm (all curves are referred to right axis) and solar irradiance $I_{S}(1$, solid, orange, $\mathbf{a}-\mathbf{f}$ all curves are referred to left axis) on wavelength $\lambda$. Horizontal solid line (black) denotes the value $P_{1}=1$ [65]
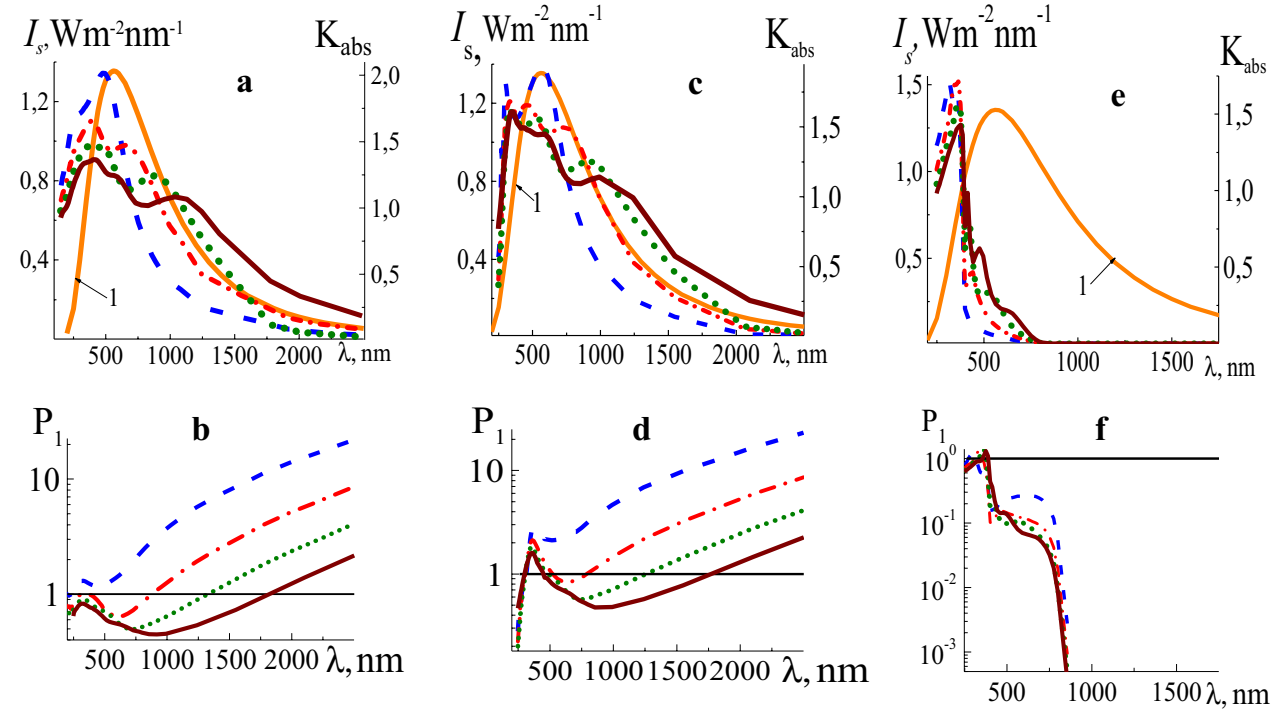

are sharply decreased in the IR spectral interval $\lambda>700 \mathrm{~nm}$ up to $\sim 3-4$ order of value that means practically insignificant absorption of solar radiation by $\mathrm{TiO}_{2}$ and $\mathrm{NiO} \mathrm{NPs}$ in this spectral interval. In general, $\mathrm{TiO}_{2}$ and $\mathrm{NiO} \mathrm{NPs}$ are therefore not suitable for absorption in solar thermal applications because of extremely low absorption in VIS and IR regions of spectrum and their parameters $P_{1} \ll 1$. Analogous conclusions can be possibly made for other different pure oxide NPs, for example, for $\mathrm{Al}_{2} \mathrm{O}_{3}, \mathrm{SiO}_{2}, \mathrm{Mo}_{2} \mathrm{O}_{3} \mathrm{NPs}$. It should be noted that pure oxide NPs were used in various experiments [43, 73-78], but without verification of the real use of them for solar effective absorption.

So, spherical $\mathrm{Ti}, \mathrm{Ti}_{-} \mathrm{TiO}_{2} \mathrm{NPs}$ and in smaller degree $\mathrm{Ni}$, $\mathrm{Ni}-\mathrm{NiO} \mathrm{NPs}$ with $r_{0}, r_{1}=50-100 \mathrm{~nm}$ can be applied as

possible candidates for effective absorption of solar radiation and can be used as good absorbers among other possible candidates.

\subsection{Indicatrices of radiation scattered by homogeneous and core-shell nanoparticles}

An NP absorbs and scatters the radiation incident on it. The radiation absorbed by an NP withdraws from the subsequent optical processes, and the scattered radiation propagates in a medium with NPs and participates in subsequent acts of absorption and scattering by NPs, etc. The scattering indicatrix shows the relative radiation 
intensity scattered by an NP in different directions in the range of variation of the scattering angles from $0^{\circ}$ to $360^{\circ}$.

In the process of light-NP interaction absorption by NPs, scattering of radiation with indicatrices close to spherical is of interest. In this case, the scattered radiation will be uniformly distributed in all directions from the scattering NP and potentially be effectively absorbed by neighboring NPs. In the case of the dominant scattering of radiation by an NP into rear or front hemisphere, the scattering processes will emit radiation from the irradiated region of the NF and sharply reduce the efficiency of the final radiation absorption by NPs.

Figure 8 shows the scattering indicatrices of radiation with wavelengths $\lambda=300$ (UV) nm, 560 (VIS) nm and 1000 (IR) $\mathrm{nm}$ for homogeneous $\mathrm{Ti}_{1} \mathrm{TiO}_{2} \mathrm{NPs}$ and two-layered
Ti-TiO ${ }_{2}$ NPs (shell thickness $\Delta r_{1}=10 \mathrm{~nm}$ ) with radii $r_{0}$, $r_{1}=50,75,100 \mathrm{~nm}$. Radiation propagates from left to right (from $180^{\circ}$ to $0^{\circ}$ ).

For all NPs with $r_{0}, r_{1}=50,100 \mathrm{~nm}$ and for $\lambda=300$, $560 \mathrm{~nm}$, the radiation scattering indicatrices are elongated forward in the direction of radiation propagation. The scattering of 560 and $1000 \mathrm{~nm}$ by NPs with $r_{0}$, $r_{1}=75 \mathrm{~nm}$ looks like more spheroidal with approximate equal scattering toward rear and front directions. The increase in wavelength leads to a certain scattering increase in the rear hemisphere for $\lambda=1000 \mathrm{~nm}$ and for all NP sizes to more uniform distribution of radiation in space and almost symmetrical picture of the scattering indicatrix. This fact means that radiation will be scattered uniformly around NPs and this situation will be more
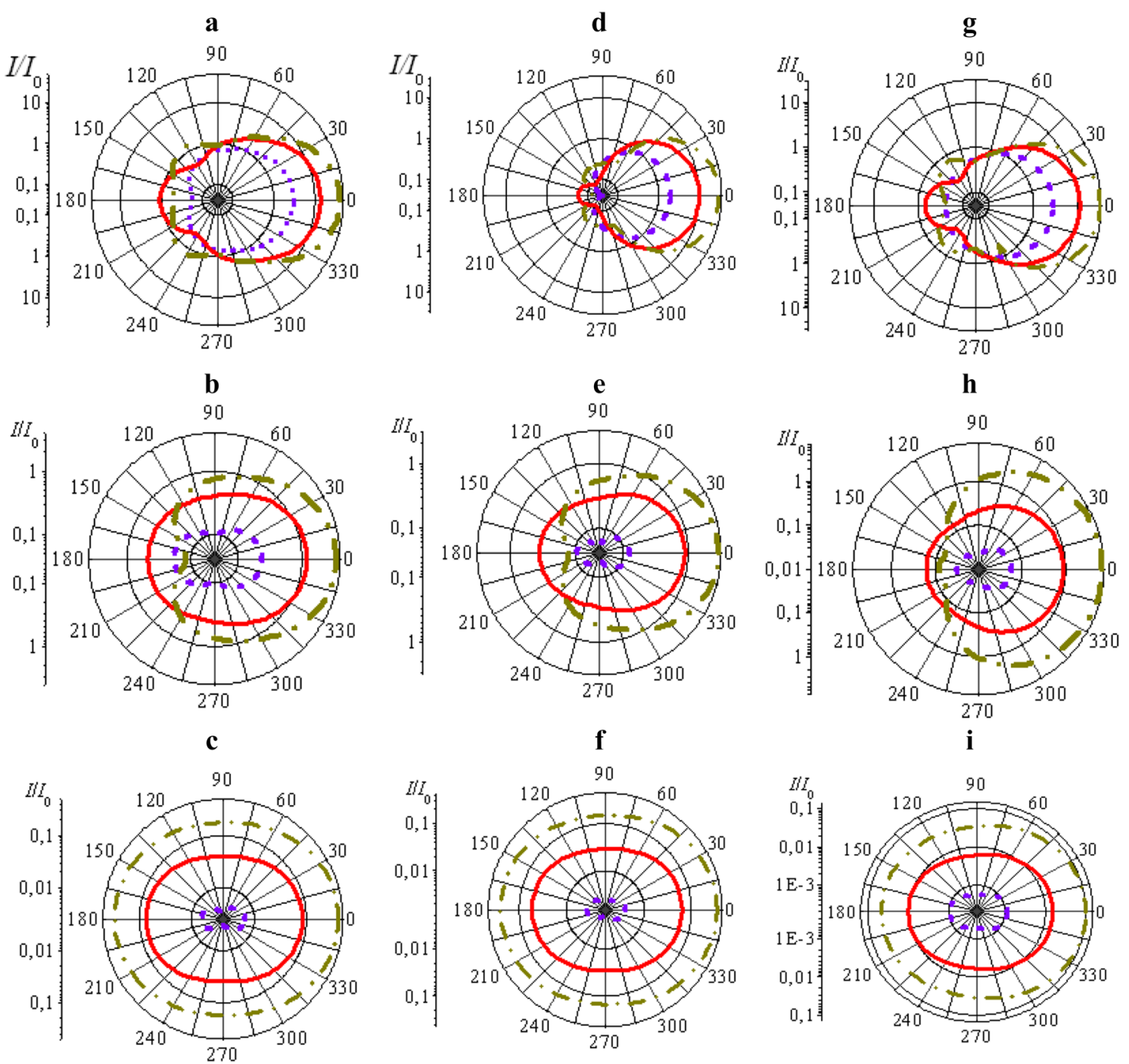

Fig. 8 Scattering indicatrices of radiation with wavelengths $\lambda=300 \mathrm{~nm}(\mathbf{a}, \mathbf{d}, \mathbf{g}), 560 \mathrm{~nm}(\mathbf{b}, \mathbf{e}, \mathbf{h}), 1000 \mathrm{~nm}(\mathbf{c}, \mathbf{f}, \mathbf{i})$ for Ti NPs (a, b, c), TiO NPs $(\mathbf{g}, \mathbf{h}, \mathbf{i})$ and Ti+TiO NPs, $\Delta r_{1}=10 \mathrm{~nm}$, with $r_{0}, r_{1}=50 \mathrm{~nm}$ (dotted, blue), $r_{0}=75 \mathrm{~nm}$ (solid, red), $r_{0}=100 \mathrm{~nm}$ (dashed-dotted, green) (d, e, f). Radiation is propagated from left to right (from $180^{\circ}$ to $\left.0^{\circ}\right)[50]$ 
appropriate for the use of solar radiation absorption by NF.

With increasing wavelength, the amount of scattered radiation decreases significantly, especially for small NP sizes. The scattering indicatrices of radiation with wavelengths $\lambda=300,560,1000 \mathrm{~nm}$ by $\mathrm{Ni}, \mathrm{NiO}, \mathrm{Ni}-\mathrm{NiO}$ NPs show the same features presented higher.

In this part, results of optical properties of core-shell and homogeneous oxide NPs [53-80] have been reviewed. Comprehensive analysis of optical properties of homogeneous metallic $\mathrm{Ti}, \mathrm{Ni}$ and oxide $\mathrm{TiO}_{2}, \mathrm{NiO} \mathrm{NPs}$ and core-shell $\mathrm{Ti}_{-} \mathrm{TiO}_{2}, \mathrm{Ni}-\mathrm{NiO} \mathrm{NPs}$ has been carried out. $\mathrm{Ti}$, $\mathrm{Ni}$ and core-shell $\mathrm{Ti}^{-\mathrm{TiO}_{2}}, \mathrm{Ni}-\mathrm{NiO} \mathrm{NPs}$ can be applied as perspective candidates for effective absorption of solar radiation. Oxide $\mathrm{TiO}_{2}$, NiO NPs cannot be used for effective absorption of solar radiation due to extremely low absorption in VIS and IR regions of spectrum. The increase in radiation wavelength leads to more uniform distribution of scattered radiation in space, and indicatrices look like more spheroidal with approximate equal scattering in rear and front directions.

\section{Optical properties of nanoparticle systems and nanofluids}

\subsection{Analysis of optical properties of nanoparticle systems and nanofluids}

Analysis of optical properties of NPs systems and NFs investigated and used in optical and solar radiation absorption applications is presented below. The extinction coefficients of NPs systems and NFs and optical transmission of the layer of NFs are investigated for the purposes of effective absorption, extinction of solar radiation and estimation of geometrical size of absorbers. Partially, this topic was reviewed in part 2 (see $[42,43,45,46,49,56,58$, $66,67,74,80])$.

A review of optical properties is presented for direct absorption of solar radiation [84]. Our review studies various NPs more widely and novel model of heating of NPs and surrounding fluid by solar radiation has been discussed. The extinction and absorption coefficients for metallic $\mathrm{Au}, \mathrm{Ag}, \mathrm{Al} \mathrm{NPs}$, oxide $\mathrm{Fe}_{2} \mathrm{O}_{3}, \mathrm{CeO}_{2} \mathrm{NPs}$ were investigated theoretically on the basis of Rayleigh and Mie approximations and experimentally on the basis of spectrophotometric and integrating sphere measurements.

A few theoretical investigations of optical properties of NPs and NFs have been carried out. Numerical investigation of the optical properties of plasmonic $\mathrm{Au}, \mathrm{Ag}, \mathrm{Cu}$ and Al NPs with radii 10-50 nm has been carried out for effective solar absorption [39]. A theoretical approach for calculation of the extinction coefficients of NFs with particle agglomeration is proposed based on diffusion limited cluster aggregation simulation and generalized multiparticle Mie solution method [89]. Mostly used models are presented along with their limitations and applications [87]. Lambert-Beer, Mie and Gans approaches and discrete dipole approximation (DDA) are employed for determination of the extinction coefficient and transmittance of Al, Ag NFs.

Experimental investigation of absorbance and transmittance in the spectral interval $200-2500 \mathrm{~nm}$ for different concentrations of Ag NPs, decorated graphene oxide nanosheets, has been carried out [88]. Experimental investigation of extinction coefficient of $\mathrm{Al}_{2} \mathrm{O}_{3}-\mathrm{CuO}$ binary NPs dispersed in ethylene glycol-water mixture has been carried out [62]. Extinction coefficients and transmittance of $\mathrm{NFs}$ from core/shell $\mathrm{NP}_{\mathrm{S}}$ for efficient trapping of solar radiation have been investigated $[56,71]$. Optical transmission measurements were performed on several water-based $\mathrm{NFs}$ of oxide $\mathrm{NPs}\left(\mathrm{Al}_{2} \mathrm{O}_{3}, \mathrm{CuO}, \mathrm{TiO}_{2}, \mathrm{ZnO}, \mathrm{CeO}_{2}\right.$ and $\left.\mathrm{Fe}_{2} \mathrm{O}_{3}\right)$ as a function of NPs concentration for application in direct absorption of solar energy [74]. Extinction coefficients and transmittance of NFs from oxide $\mathrm{NP}_{\mathrm{S}}$ for efficient absorption of solar radiation have been investigated $[73,75]$.

The optical properties (absorption, transmittance and extinction coefficient) of NFs based on metal, metal oxide, etc. have been thoroughly reviewed in variation with particle size and shape, path length and volume fraction [86]. Optical solar absorption was increased with increasing NP size and volume concentration, and the transmittance of NFs has indirect relation with NP size, volume fraction.

\subsection{Optical properties of selected nanoparticle systems and nanofluids for effective absorption of solar radiation}

A complex and extensive discussion of the selection of spherical metallic and metal-its oxide core-shell NPs and NFs containing these NPs is carried out below. It is interesting to determine the contribution of fluid (water) and NPs separately and totally in absorption, scattering and extinction of solar radiation in the whole spectral interval of 200-2500 nm [36, 37].

Figure 9 presents the dependencies of solar irradiance $I_{S}$ on $\lambda$, the dependencies of the coefficients of scattering $\alpha_{\mathrm{sca}}^{\mathrm{W}}$ and absorption $\alpha_{\mathrm{abs}}^{\mathrm{W}}$ of radiation by water [7] and the calculated spectral coefficients of absorption $\alpha_{\mathrm{abs}}^{\mathrm{N}}=\pi N_{0} r_{0}^{2} K_{\mathrm{abs}}\left(r_{0}, \lambda\right)$ and scattering $\alpha_{\mathrm{sca}}^{\mathrm{N}}=\pi N_{0} r_{0}^{2} K_{\text {sca }}\left(r_{0}, \lambda\right)$ of radiation by Ti NPs, $\mathrm{Ti}-\mathrm{TiO}_{2} \mathrm{NP}$ systems with the radii $r_{0}, r_{1}=50,125 \mathrm{~nm}$, NP concentrations $N_{0}=1 \cdot 10^{9} \mathrm{~cm}^{-3}$ and with $r_{0}, r_{1}=75 \mathrm{~nm}$ and $N_{0}=1 \cdot 10^{9}, 1 \cdot 10^{10} \mathrm{~cm}^{-3}$.

Optical coefficients for core-shell NP systems are determined the same expressions as for homogeneous NPs but 
Fig. 9 Dependencies of the coefficients of radiation absorption $\alpha_{\text {abs }}^{\mathrm{N}}$ (solid, red 1, 2) and scattering $\alpha_{\text {sca }}^{\mathrm{N}}$ (dashed, brown, 1, 2) by Ti $(\mathbf{a}, \mathbf{b})$ and $\mathrm{Ti}^{-\mathrm{TiO}_{2}}$ (c, d), $\Delta r_{1}=10 \mathrm{~nm}, \mathrm{NP}$ systems with the radii $r_{0}, r_{1}=50$ (1), 125 (2) $\mathrm{nm}, N_{0}=1 \cdot 10^{9} \mathrm{~cm}^{-3}$ $(\mathbf{a}, \mathbf{c})$ and with the radii $r_{0}$, $r_{1}=75 \mathrm{~nm}, N_{0}=1 \cdot 10^{9}(1), 1 \cdot 10^{10}$ (2) $\mathrm{cm}^{-3}(\mathbf{b}, \mathbf{d})$, the coefficients of absorption $\alpha_{a b s}^{W}$ (3, solid, blue a-d) and scattering $\alpha_{s c a}^{W}(3$, dashed, blue $\mathbf{a}-\mathbf{d}$ ) radiation by water (all curves are referred to left axis) and solar irradiance $I_{\mathrm{S}}$ on $\lambda$ (4, solid, orange, a-d, all curves are referred to right axis) $[65,66]$
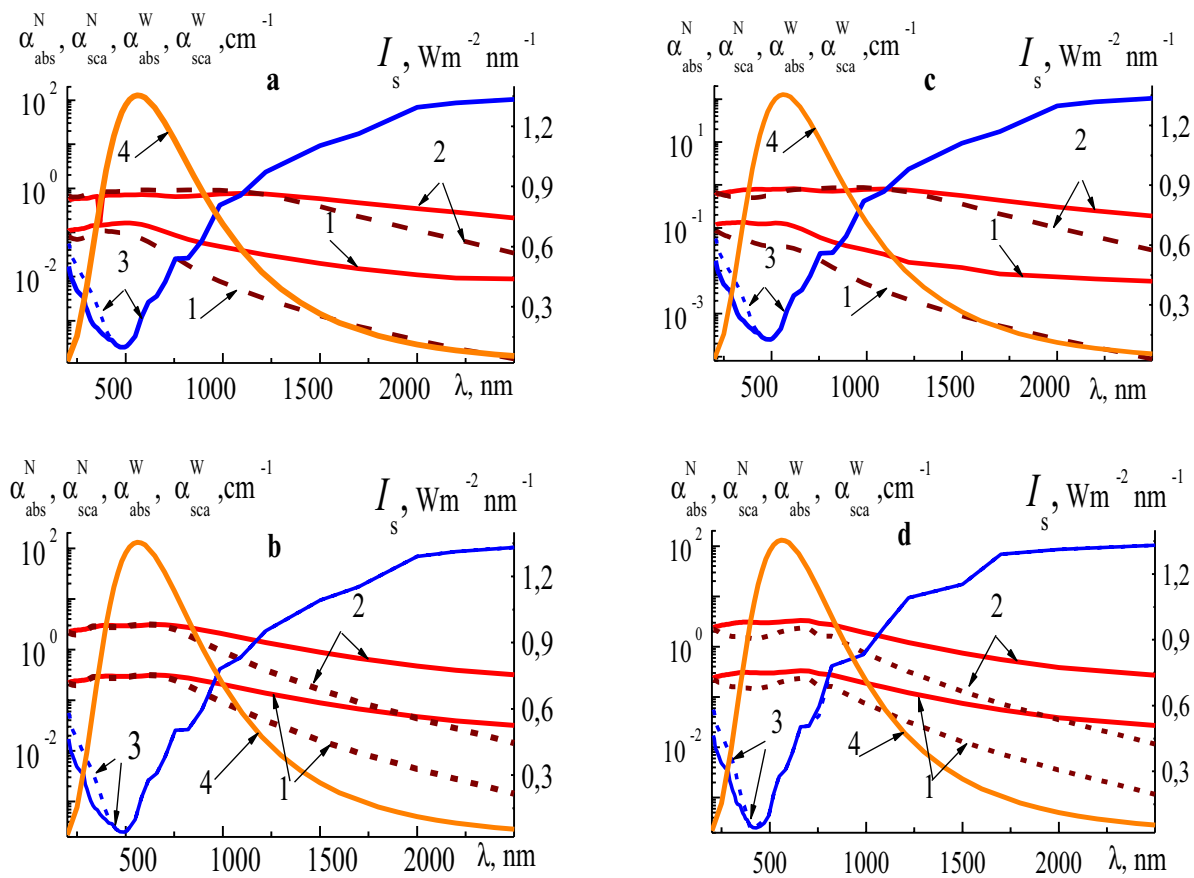

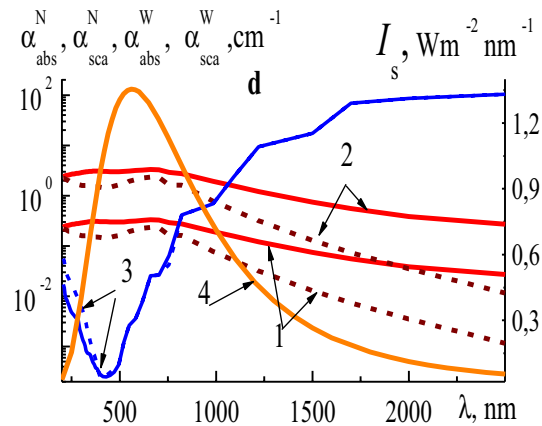

with substitution $r_{0}$ to $r_{1}$. The influence of $r_{0}, r_{1}$ on optical properties of NFs is analyzed under constant values of $\mathrm{N}_{0}=1 \cdot 10^{9} \mathrm{~cm}^{-3}$ (Fig. 9a, c). Radiation scattering by water is significant only in the UV spectral region $200-400 \mathrm{~nm}$ (see Fig. 9), and it is approximately equal to zero for $\lambda>500 \mathrm{~nm}$.

Increasing $r_{0}, r_{1}$ of mentioned NPs from $50 \mathrm{~nm}$ till $125 \mathrm{~nm}$ leads to increasing spectral interval from $\sim 200-900 \mathrm{~nm}$ till 200-1200 nm in which radiation absorption by $\mathrm{Ti}$ and $\mathrm{Ti}_{-}-\mathrm{TiO}_{2}$ NPs dominates absorption by water $\alpha_{\mathrm{abs}}^{\mathrm{W}}$ for $N_{0}=1 \cdot 10^{9} \mathrm{~cm}^{-3}$. As a result, solar radiation absorption by $\mathrm{NF}$ in the presented spectral intervals is determined by dominated influence of NPs.

On the other hand, water is the dominating factor in radiation absorption in the spectral intervals $\lambda>900$ (containing $\sim 38 \%$ of whole solar radiation energy) or $\lambda>1200$ ( $\sim 20 \%$ solar energy) $\mathrm{nm}$ in comparison with NPs with $r_{0}$, $r_{1}=50 \mathrm{~nm}$ and $r_{0}, r_{1}=125 \mathrm{~nm}$ accordingly.

The radiation absorption coefficient for water $\alpha_{\mathrm{abs}}^{\mathrm{W}}$ sharply increases with the increase in $\lambda$ and $\alpha_{\mathrm{abs}}^{\mathrm{W}}$ is larger than $10^{1} \mathrm{~cm}^{-1}$ in the spectral range $\lambda>1400 \mathrm{~nm}$. Therefore, absorption of solar radiation in this interval is realized in water thin layer with the thickness of about $\sim 1 / \alpha_{\mathrm{abs}}^{\mathrm{W}} \sim 10^{-1}-10^{-2} \mathrm{~cm}$, which prevents the realization of volumetric absorption of solar radiation. This is the main problem for the use of water or water-based fluid for volumetric absorption of solar radiation in spectral interval $\lambda>1400 \mathrm{~nm}$.

The influence of the values of $\mathrm{N}_{0}=1 \cdot 10^{9}, 1 \cdot 10^{10} \mathrm{~cm}^{-3}$ on optical properties of NFs is analyzed here under constant value $r_{0}, r_{1}=75 \mathrm{~nm}$ (Fig. 9b, d). In the spectral intervals $\sim 200-900$ and $\sim 200-1200 \mathrm{~nm}$, solar radiation absorption by water is much smaller than radiation absorption by both types of NP systems with concentration $N_{0}=1 \cdot 10^{9}$ and $1 \cdot 10^{10} \mathrm{~cm}^{-3}$ accordingly and solar radiation absorption is determined by the influence of NPs. However, in the spectral interval $\lambda>900 \mathrm{~nm}$ and $\lambda>1200 \mathrm{~nm}$, water is the dominating factor in radiation absorption in comparison with mentioned NP systems.

Figure 10a-d shows the spectrum of the solar irradiance $I_{s}(\lambda)$ on wavelength $\lambda$ and the spectral dependencies of the coefficients of radiation extinction by water $\left(\alpha_{\text {ext }}^{\mathrm{W}}\right)$ and by the systems of $\mathrm{Ti}$ and $\mathrm{Ti}+\mathrm{TiO}_{2} \mathrm{NPs}\left(\alpha_{\text {ext }}^{\mathrm{N}}\right)$ with $r_{0}, r_{1}=50,125 \mathrm{~nm}$ at concentration of $N_{0}=1 \cdot 10^{9} \mathrm{~cm}^{-3}(\mathrm{a}$, c) and with $r_{0}, r_{1}=75 \mathrm{~nm}$ for NP concentrations $\mathrm{N}_{0}=1 \cdot 10^{9}$, $1 \cdot 10^{10} \mathrm{~cm}^{-3}(\mathrm{~b}, \mathrm{~d})$, the total coefficient of radiation extinction by NFs $\alpha_{\text {ext }}=\alpha_{\text {ext }}^{\mathrm{N}}+\alpha_{\text {ext }}^{\mathrm{W}}$ with systems of $\mathrm{Ti}, \mathrm{Ti}+\mathrm{TiO}_{2}$ NPs. Spectral dependence of radiation extinction by water $\alpha_{\text {ext }}^{\mathrm{W}}$ on $\lambda$ practically coincides with the dependence $\alpha_{\mathrm{abs}}^{\mathrm{W}}(\lambda)$.

The extinction of solar radiation by water in the spectral ranges $\sim 200-900 \mathrm{~nm}$ and $\sim 200-1200 \mathrm{~nm}$ is smaller than that of $\mathrm{Ti}, \mathrm{Ti}+\mathrm{TiO}_{2} \mathrm{NPs}$ with $r_{0}, r_{1}=50 \mathrm{~nm}$ and $r_{0}, r_{1}=125 \mathrm{~nm}$ accordingly. As a result, the extinction of the radiation in the mentioned spectral ranges is determined by the dominant influence of the system of NPs and $\alpha_{\text {ext }} \approx \alpha_{\text {ext }}^{\mathrm{N}}$.

Water dominantly influences on the radiation extinction by NF in the spectral range $\lambda>900 \mathrm{~nm}$ and $\lambda>1200 \mathrm{~nm}$, and NF extinction coefficient $\alpha_{\text {ext }}$ is practically equal to $\alpha_{\text {ext' }}^{\mathrm{W}} \alpha_{\text {ext }} \approx \alpha_{\text {ext }}^{\mathrm{W}}$ and for $\lambda>1400 \mathrm{~nm} \alpha_{\text {ext }}^{\mathrm{W}} \sim 10^{1}-10^{2} \mathrm{~cm}^{-1}$ [7]. The spectral interval $\lambda \sim 1100-1300 \mathrm{~nm}$ is a transition zone from the dominant influence of NPs to the dominant influence of water on solar radiation absorption and extinction. 
Fig. 10 Dependencies of the coefficients of radiation extinction $\alpha_{\text {ext }}^{\mathrm{N}}$ (dashed-dotted, red) by $\mathrm{Ti}(\mathbf{a}, \mathbf{b})$ and $\mathrm{Ti}_{-} \mathrm{TiO}_{2}$ (c, d), $\Delta r_{1}=10 \mathrm{~nm}, \mathrm{NP}$ systems with the radii $r_{0}, r_{1}=50(1), 125$ (2) $\mathrm{nm}, N_{0}=1 \cdot 10^{9} \mathrm{~cm}^{-3}(\mathbf{a}, \mathbf{c})$ and with radii $r_{0}, r_{1}=75 \mathrm{~nm}$, $N_{0}=1 \cdot 10^{9}(1), 1 \cdot 10^{10}(2) \mathrm{cm}^{-3}$ $(\mathbf{b}, \mathbf{d})$, coefficient of radiation extinction by water $\alpha$ w (dashed-dotted, blue a-d) and total coefficient of radiation extinction $\alpha_{\text {ext }}=\alpha_{\text {ext }}^{\mathrm{N}}+\alpha_{\text {ext }}^{\mathrm{W}}$ by NF (3, solid, brown), all curves are referred to left axis, and solar irradiance Is $(4$, solid, orange a-d, all curves are referred to right axis) $[65,67]$
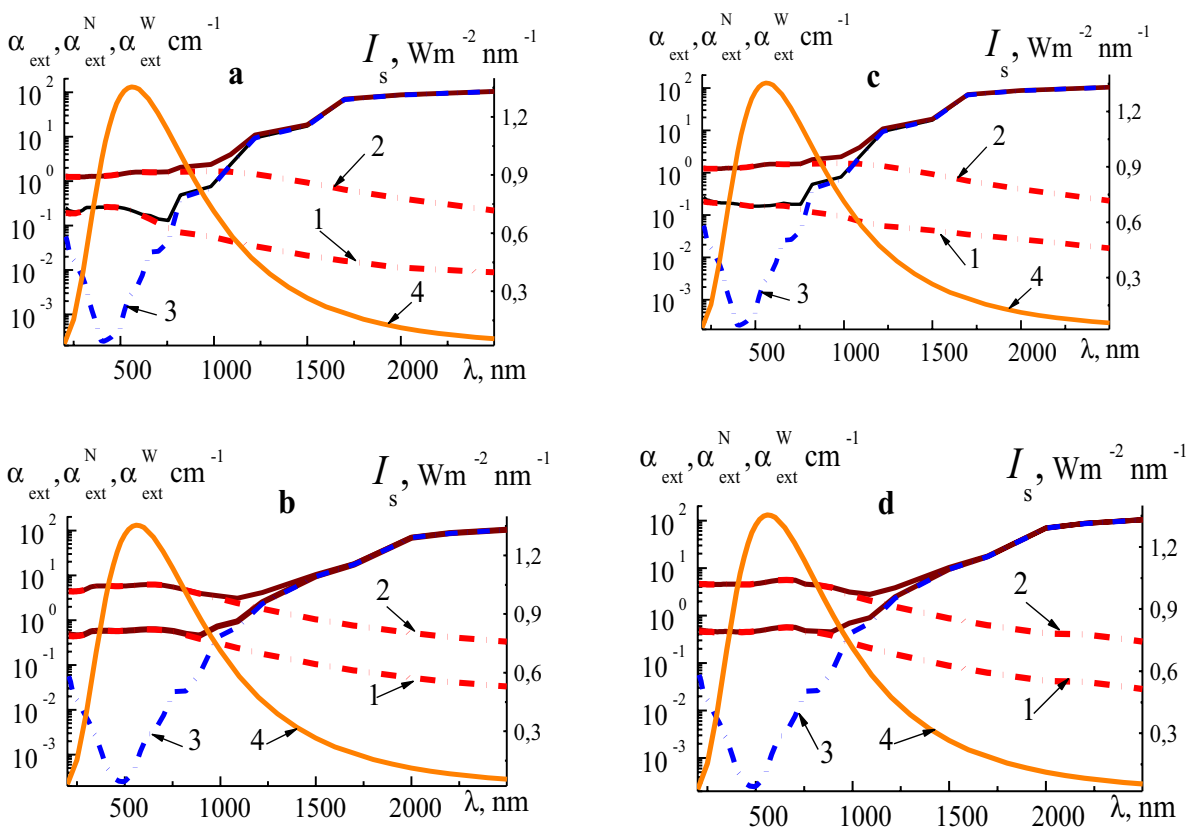

Consequently, the extinction of the solar radiation will occur in a thin layer of water with a thickness of about $\sim 10^{-1}-10^{-2} \mathrm{~cm}$ in the indicated interval. It is impossible to use the radiation absorption in the range of $1200-2500 \mathrm{~nm}$ by an NF based on water for volumetric absorption of radiation or moreover to use additional absorbers (NPs).

Analogous theoretical and experimental investigation of the radiation absorption characteristics of a Ni nanoparticle suspension was carried out by spectroscopic transmission measurement [46]. Ni nanoparticles having average diameter of $4.9 \mathrm{~nm}$ were dispersed in alkyl naphthalene with volume fraction of $0.001\left(N_{0}=110^{16} \mathrm{~cm}^{-3}\right)$. Figure 11 shows measured absorption coefficients of the Ni nanoparticle suspension and the base fluid, and analytically predicted absorption coefficient of a cloud of nanoparticles. The absorption coefficient of a particle cloud of $\mathrm{Ni}$ nanoparticles was calculated by the Mie scattering theory under the assumption of independent scattering.

The absorption cross section of a Ni nanoparticle increases toward the shorter wavelength range. As outlined in Fig. 11, the radiation characteristics predicted by the Mie theory showed good agreement between the model and optical measurements with the increase in absorption coefficient due to nanoparticle suspension in visible and near-infrared wavelengths in which most solar radiation energy is included. The base fluid was transparent and the absorption coefficient was relatively low from visible wavelengths to around $1.6 \mu \mathrm{m}$, whereas the absorption coefficient of the nanoparticle suspension was significantly larger than that of the base fluid. At the same time,

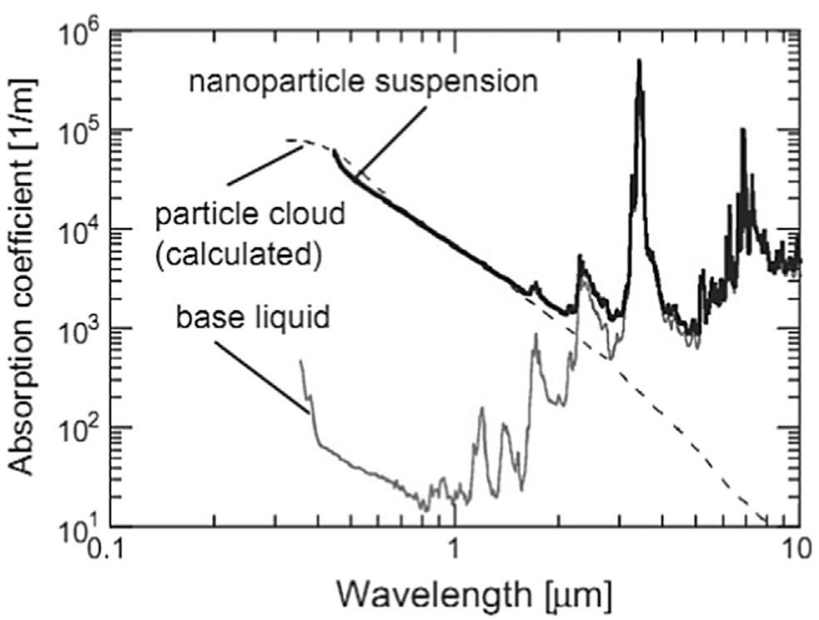

Fig. 11 Calculated absorption coefficient for a $\mathrm{Ni}$ nanoparticle cloud compared with the experimental data [46]

absorption coefficient of the suspension in the infrared region remains the same as one of the base fluid. Enhancement of solar radiation absorption using a nanoparticle suspension has been demonstrated.

Publications on optical properties of homogeneous metallic and core-shell systems NPs and NFs $[46,56,62$, 71-75, 84-91] have been reviewed in this part. The optical properties of NFs in near-UV, VIS and IR radiation intervals are determined by the total action of optical properties of water (fluid) and NPs system. The absorption and extinction of radiation by a system of NPs and the surrounding fluid are complementary and, at the same time, competitive processes in the absorption and extinction 
of solar radiation by NFs. Light absorption conditions for NFs include dominant radiation absorption by NPs with selected properties and concentrations compared to the solar absorption by water in the spectral intervals $200-900$ (200-1200) nm. These results allow us to evaluate the characteristics of NP systems and NFs with selected values of $\mathrm{N}_{0}, r_{0}, r_{1}$, types of NPs and the NF layer thickness as effective volumetric absorber.

\section{Heating of nanoparticle system and surrounding fluid by solar radiation}

\subsection{Analysis of the properties of nanoparticle systems and nanofluids}

Properties of NP systems and NFs were investigated in optical and solar radiation absorption and their heating applications during previous years [34, 92-100]. The photothermal conversion efficiency (PTE) of gold NFs has been investigated both experimentally and theoretically under natural solar irradiation conditions $[34,100]$. The PTE of gold NFs was found to be much higher than that of pure water and increased nonlinearly with the NP concentration [100].

The thermal simulation of suspended $\mathrm{SiO}_{2} / \mathrm{Ag} \mathrm{NPs}$ showed a uniform temperature rise under solar irradiation and exhibits a higher photothermal performance [101]. Optical nanostructures can control the optical absorption and are therefore being investigated for solar thermal applications with design of optical nanostructures [104]. The photothermal conversion efficiency of $\mathrm{CuO} /$ Ag plasmonic NF is higher than that of $\mathrm{CuONF}$ under the same conditions and is proportional to NPs concentration [105]. The photothermal conversion performance of six commonly used materials ( $\mathrm{Ag}, \mathrm{Fe}, \mathrm{Zn}, \mathrm{Cu}, \mathrm{Si}_{1} \mathrm{Al}_{2} \mathrm{O}_{3}$ ) in direct absorption solar collectors was experimentally investigated under a focused simulated solar flux of 12 Suns [106]. It should be noted that the processes of radiation absorption by NPs and NFs, their heating and thermal conversion were investigated insufficiently, but the results of these processes will determine the success of NP solar applications.

\subsection{Heating of nanoparticle system and surrounding fluid by solar radiation}

The main goal of solar light-to-thermal energy conversion is to achieve maximum value of NP and fluid temperatures under solar radiation action. The heating of NPs is determined by their absorption of solar radiation and simultaneously by heat transfer (thermal conduction) from NPs to ambient fluid and its heating, including also absorption of solar radiation by fluid. Novel model of NPs and NFs heating by solar radiation is analyzed below in detail.

The absence of temperature gradient and uniform irradiation by solar radiation inside absorber volume, and mono-dispersed system of NPs with one NP size are used as assumptions for the simplification of system of equations. The heating of NPs and fluid is described by next system of equations taking into account all made assumptions [97]

$\rho_{0} C_{0} V_{0} \frac{\mathrm{d} T_{0}}{\mathrm{~d} t}=\pi_{0} r_{0}^{2} \int_{\lambda_{1}}^{\lambda_{2}} I_{\mathrm{S}}(\lambda) K_{\mathrm{abs}}\left(r_{0}, \lambda\right) \mathrm{d} \lambda-J_{C} S_{0}$

$c_{\mathrm{m}} \rho_{\mathrm{m}} \frac{\partial T_{\mathrm{m}}}{\partial t}=N_{0} J_{\mathrm{C}} S_{0}+\int_{\lambda_{1}}^{\lambda_{2}} \alpha_{\mathrm{abs}}^{\mathrm{W}}(\lambda) I_{\mathrm{S}}(\lambda) \mathrm{d} \lambda$

with the initial conditions:

$T_{0}(t=0)=T_{\infty}, T_{\mathrm{m}}(t=0)=T_{\infty}$

where $\rho_{0}, c_{0}$ and $c_{m}, \rho_{\mathrm{m}}$ are density and heat capacity of NP material and ambient fluid (water) accordingly [108], $S_{0}=4 \pi r_{0}^{2}$ is the surface area, $V_{0}=4 / 3 \pi r_{0}^{3}$ is the volume of spherical NP of radius $r_{0}, T_{0}$ is the NP temperature uniformed over its volume, $T_{\mathrm{m}}$ is the surrounding medium temperature, $T_{\infty}$ is the initial NP and surrounding medium temperatures, the wavelengths $\lambda_{1}, \lambda_{2}$ mean the boundaries of optical spectrum under consideration and $J_{C}$ is the loss energy density flux from NP surface due to heat conduction. $N_{0}, I_{\mathrm{s}}, K_{\mathrm{abs}}(\lambda), \alpha_{\mathrm{abs}}^{\mathrm{W}}$ are denoted before.

The value of $J_{C}$ at NP surface is determined by quasistationary solution of heat conduction equation in spherical case [20] taking into account the heating of fluid with temperature $T_{\mathrm{m}}=T_{\mathrm{m}}(\mathrm{t})$.

$J_{\mathrm{C}}=\frac{k_{\mathrm{m}}}{r_{0}}\left(T_{0}-T_{\mathrm{m}}\right)$

where $k_{\mathrm{m}}$ is a constant thermal conduction coefficient of fluid [109]. The expression:

$q_{\mathrm{abs}}=\pi r_{0}^{2} \int_{\lambda_{1}}^{\lambda_{2}} I_{\mathrm{s}}(\lambda) K_{\mathrm{abs}}\left(r_{0}, \lambda\right) \mathrm{d} \lambda$

will be used further and $q_{\text {abs }}$ can be viewed as integral of power of solar irradiance absorbed by NP.

Solar radiation extinction (absorption) in the spectral interval $200-1200 \mathrm{~nm}$ is determined by dominated influence of the NPs system in water. Solar radiation absorption by water is much smaller than radiation absorption by NPs 
(see part 4), and $\alpha_{\mathrm{abs}}^{\mathrm{W}}$ can be neglected in Eq. (3). As a result of this simplification, the solutions for $T_{0}, T_{\mathrm{m}}$ from (2-5) have the forms [107]:

$T_{0}=T_{\infty}+\frac{\mathrm{q}_{\mathrm{abs}} N_{0}}{c \rho} t-\frac{\mathrm{q}_{\mathrm{abs}}\left(c_{\mathrm{m}} \rho_{\mathrm{m}}\right)^{2}}{4 k_{\mathrm{m}} \pi r_{0}(c \rho)^{2}}\left[\exp \left\{-\frac{t}{\tau_{\mathrm{m}}}\right\}-1\right]$

$T_{\mathrm{m}}=T_{\infty}+\frac{\mathrm{q}_{\mathrm{abs}} N_{0}}{c \rho} t+\frac{\mathrm{q}_{\mathrm{abs}} c_{\mathrm{m}} \rho_{\mathrm{m}} N_{0} c_{0} \rho_{0} V_{0}}{4 k_{\mathrm{m}} \pi r_{0}(c \rho)^{2}}\left[\exp \left\{-\frac{t}{\tau_{\mathrm{m}}}\right\}-1\right]$

$c \rho=c_{\mathrm{m}} \rho_{\mathrm{m}}+4 \pi r_{0}^{3} c_{0} \rho_{0} N_{0} / 3$ is the heat capacity of the heterogeneous NF. The characteristic time $\tau_{\mathrm{m}}=\frac{c_{0} \rho_{0} r_{0}^{2} c_{\mathrm{m}} \rho_{\mathrm{m}}}{3 k_{\infty} c \rho}=\tau_{0} \frac{c_{\mathrm{m}} \rho_{\mathrm{m}}}{c \rho}$ determines the dependencies of temperatures $T_{0}$ and $T_{1}$ on time $t$. The values of $\tau_{\mathrm{m}}$ are accordingly equal to $\approx 3.710^{-9}, 1.510^{-8} \mathrm{~s}$ for $r_{0}=50$, $100 \mathrm{~nm}$. The use of core-shell NPs leads to analogous solutions with some deviations in designations.

The dependence of NP overheating $\Delta T=T_{0}-T_{\mathrm{m}}$ relatively water temperature $T_{\mathrm{m}}$ on time $t$ [see (7)] is determined

$\Delta T=T_{0}-T_{\mathrm{m}}=\frac{\mathrm{q}_{\mathrm{abs}} c_{\mathrm{m}} \rho_{\mathrm{m}}}{4 k_{\mathrm{m}} \pi r_{0} c \rho}\left[1-\exp \left\{-\frac{t}{\tau_{\mathrm{m}}}\right\}\right]$

The dependence of normalized NP overheating $\Delta T_{n}$ by solar radiation on time $t$ is equal

$\Delta T_{\mathrm{n}}=\Delta T / \frac{\mathrm{q}_{\mathrm{abs}} c_{\mathrm{m}} \rho_{\mathrm{m}}}{4 k_{\mathrm{m}} \pi r_{0} c \rho}=1-\exp \left\{-\frac{t}{\tau_{\mathrm{m}}}\right\}$

Conversion of light energy starts with photo-induced generation of energy-rich electrons and ultrafast electron dynamics in NPs [102]. The dependencies of $\Delta T_{n}$ for Ti NPs with $r_{0}=50,100 \mathrm{~nm}$, immersed in water, are presented in Fig. 12a. The increase in $\Delta T_{\mathrm{n}}$ begins from time instant $t \sim 10^{-9}, 10^{-10} \mathrm{~s}$, and $\Delta T_{\mathrm{n}}$ achieves own maximal value of $\Delta T_{\mathrm{n}}=1$ at $t \sim 10^{-8}, 10^{-7} \mathrm{~s}$ for $r_{0}=50,100 \mathrm{~nm}$ accordingly. After achievement of maximal NP overheating relatively fluid, the equivalence has been established between absorption radiation energy by NP and heat loss from NP by heat conduction.

For solar radiation action, the condition $t \gg \tau_{m}$ is obeyed and the dependencies of temperatures $T_{0}, T_{\mathrm{m}}$ (7) are transformed:

$T_{0} \approx T_{\infty}+\frac{\mathrm{q}_{\mathrm{abs}} N_{0}}{c \rho} t+\frac{\mathrm{q}_{\mathrm{abs}}\left(c_{\mathrm{m}} \rho_{\mathrm{m}}\right)^{2}}{4 k_{\mathrm{m}} \pi r_{0}(c \rho)^{2}}$

$T_{\mathrm{m}} \approx T_{\infty}+\frac{\mathrm{q}_{\mathrm{abs}} N_{0}}{c \rho} t-\frac{\mathrm{q}_{\mathrm{abs}} c_{\mathrm{m}} \rho_{\mathrm{m}} N_{0} c_{0} \rho_{0} V_{0}}{4 k_{\mathrm{m}} \pi r_{0}(c \rho)^{2}}$

The temperatures $T_{0}$ and $T_{\mathrm{m}}$ increase in time $t$ due to the condition of absence of heat loss outside the irradiated
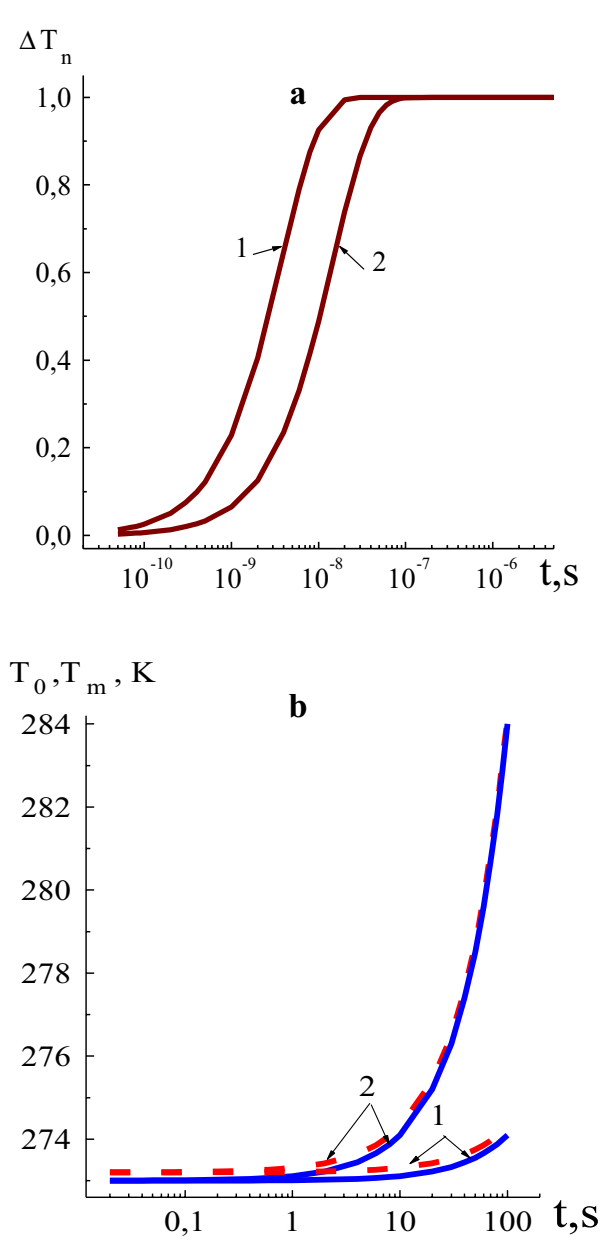

Fig. 12 The temporal dependencies of normalized NP overheating $\Delta T_{\mathrm{n}}$ [see (9), green] for Ti NPs with $r_{0}=50$ (1), 100 (2) nm immersed in water (a) and of the temperatures $T_{0}$ (dashed, red) of Ti NPs system with $r_{0}=100 \mathrm{~nm}, N_{0}=1 \cdot 10^{9}(1), 1 \cdot 10^{10}(2) \mathrm{cm}^{-3}$ and $T_{m}$ (solid, blue) of surrounding water [see (10)], which are heated by solar radiation [107]

volume, and this solution is applicable for period of time till thermal energy loss out of absorber volume is negligible. The temperatures $T_{0}, T_{\mathrm{m}}$ are proportional to the NP concentration $N_{0}$.

Stationary overheating of NPs in comparison with fluid $T_{0}-T_{\mathrm{m}}$ for $\left.t\right\rangle T_{\mathrm{m}}$ is constant during the radiation action [see also $\Delta T(8)]$ :

$\Delta T=T_{0}-T_{\mathrm{m}}=\frac{\mathrm{q}_{\mathrm{abs}} c_{\mathrm{m}} \rho_{\mathrm{m}}}{4 k_{\mathrm{m}} \pi r_{0} c \rho}$

Figure $12 \mathrm{~b}$ presents the temporal dependencies of the temperatures $T_{0}$ of the Ti NPs system with $r_{0}=100 \mathrm{~nm}$, $N_{0}=1.10^{10}, 1.10^{9} \mathrm{~cm}^{-3}$ and $T_{\mathrm{m}}$ of surrounding water (10), which are heated by solar radiation.

The heating of the NPs by solar irradiation, their intensive heat exchange with the surrounding water and following its heating starts after characteristic time 
$t \sim \tau_{\mathrm{m}} \approx 1.5 \cdot 10^{-8} \mathrm{~s}$ (see Fig. 12a) from irradiation commencement. The energy release in NPs and their heat exchange lead to the increase in the temperatures $T_{0}$ and $T_{m}$ in time with small difference between them due to intense heat exchange of NPs with surrounding water.

It should be taken into account that thermal energy of volume unit of surrounding water at initial temperature $T_{\infty}=273 \mathrm{~K}$ is equal to $E_{\mathrm{m} \infty}=c_{\mathrm{m}} \rho_{\mathrm{m}} T_{\infty}=1.14 \cdot 10^{3} \mathrm{~J} /$ $\mathrm{cm}^{3}$ and it is much larger than the thermal energy $E_{0 \infty}=N_{0} c_{0} \rho_{0} \mathrm{~V}_{0} T_{\infty}=3.13 \cdot 10^{-2} \mathrm{~J} / \mathrm{cm}^{3}$ of Ti NP system with high values of $r_{0}=100 \mathrm{~nm}$ and $N_{0}=1 \cdot 10^{10} \mathrm{~cm}^{-3}$.

Due to this reason, remarkable heating of water commences only from the moment $t \sim 1 \mathrm{~s}$ after radiation action, when the value of thermal energy transferred from NP system to water till this moment is sufficient to increase water temperature $T_{\mathrm{m}}$ because of great difference between heat capacities of fluid and NP system mentioned above. Temperatures $T_{0}$ and $T_{\mathrm{m}}$ achieve the value of about $\sim 283 \mathrm{~K}$ $\left(T_{\infty}=273 \mathrm{~K}\right)$ at $\mathrm{t} \sim 100 \mathrm{~s}$ for $N_{0}=1 \cdot 10^{10} \mathrm{~cm}^{-3}, r_{0}=100 \mathrm{~nm}$. The results in Fig. 12a, b are presented for Ti NPs, but their important features are applicable for various NPs with analogous values of NP and NF parameters.

It should be noted that the temporal linear dependence of $T_{0}, T_{\mathrm{m}}$ has been experimentally established [109-111] for initial period of heating, which confirms the dependencies (10). The temperature curves are shown in Fig. 13, which clearly shows that Au NPs had good photothermal conversion capability under the xenon lamp radiation [109]. There was a temperature limitation for Au NPs, which was depended on the shape and size of Au NPs, the radiation intensity and the ambient temperature. Under the intense and long enough illumination, the process of temperature changed consisted of the following procedures: (i) temperature increased with time; (ii) Au NPs reached their own photothermal conversion limitation, taking into account the heat losses, and had constant conversion efficiency, but the temperature still increased and (iii) the temperature became constant when the absorption and dissipation of energy reached equilibrium. In the process of (ii) and (iii), the rate of rise in temperature slowed down until reaching the point of energy balance. The temperature change in Au NPs with different sizes could be calculated by Eq. (10) during the process (i), when temperature increased with time.

As it was mentioned above, water is the dominating factor in solar radiation absorption in the spectral interval $1200<\lambda<2500 \mathrm{~nm}$ and absorption of solar radiation in whole spectral interval $200-2500 \mathrm{~nm}$ will be realized in thin water layer with the thickness of about 1/ $\alpha_{\mathrm{abs}}^{\mathrm{W}} \sim 10^{-1}-10^{-2} \mathrm{~cm}$. The NPs, placed in this thin layer, undergo by solar radiation with the wavelengths in the spectrum 200-2500 nm. NPs located in the deep layers with the depth larger than $1 / \alpha_{\mathrm{abs}}^{\mathrm{W}}$ absorb radiation only in the spectral interval $\sim 200-1200 \mathrm{~nm}$ penetrating in deep water layers.

Figure 14 presents the dependencies of $q_{\mathrm{abs}} q_{\mathrm{abs}} / \pi r_{0}$ on $r_{0}$ for homogeneous Ti, Au NPs and $q_{\mathrm{abs}}, q_{\mathrm{abs}} / \pi r_{1}$ on $r_{1}$ for core-shell $\mathrm{Ti}_{-} \mathrm{TiO}_{2}$ NPs for two different cases-(a) for NPs placed in surface layer irradiated with wavelengths in the interval 200-2500 nm, (b) for NPs in the deep layers of water volume irradiated with $200-1100 \mathrm{~nm}$. Figure 14 is transformed from Figs. 3 and 4 [97]. Results for Au NPs are presented for comparison. The expression of $q_{\text {abs }}$ determines the energy release in NPs (10), the rate of NPs and NF heating, the quantitative values and temporal dependencies of $T_{0}, T_{\mathrm{m}}$ (7-11). The combinations of $q_{\mathrm{abs}} / \pi r_{0}$ and $q_{\mathrm{abs}} / \pi r_{1}$ determine the value of NP overheating in comparison with fluid $\Delta T, \Delta T_{\mathrm{n}}(8,9)$ and also the influence on temporal dependencies $T_{0}, T_{\mathrm{m}}$ on $t(7,10)$. a

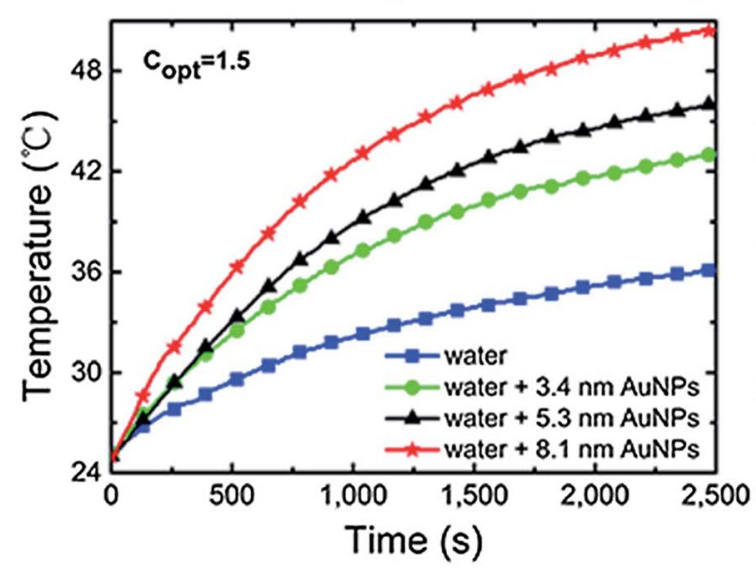

b

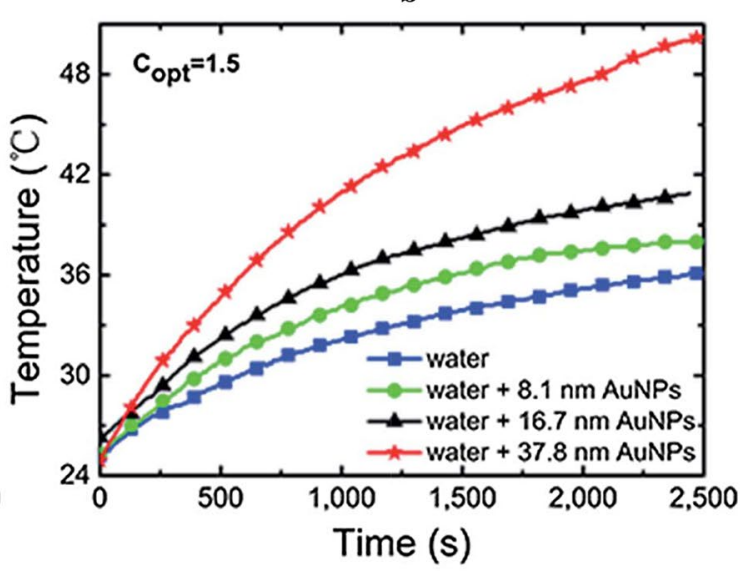

Fig. 13 Temperature changes with time for Au NFs from two different groups G1 (a) and G2 (b) under $1.5 \mathrm{~kW} \mathrm{~m}^{-2}$ illumination [109] 
Fig. 14 The dependencies of $q_{\mathrm{abs}}$ (solid, red), $P_{1}$ (dashed, brown) on $r_{0}, r_{1}$ accordingly, horizontal solid lines (black) denote the value of $P_{1}=1$ $(\mathbf{a}, \mathbf{b})$ and the dependencies of $q_{\mathrm{abs}} / \pi r_{0}, \mathrm{q}_{\mathrm{abs}} / \pi r_{1}$ on $r_{0}, r_{1}$ (solid, red c, d) accordingly for homogeneous Ti (1), Au (3) NPs and for core-shell $\mathrm{Ti}^{-\mathrm{TiO}_{2}}$ (2), $\Delta r_{1}=10 \mathrm{~nm}, \mathrm{NPs}$ in the spectral intervals $200-1100 \mathrm{~nm}(\mathbf{a}, \mathbf{c})$ and $200-2500 \mathrm{~nm}(\mathbf{b}, \mathbf{d})$
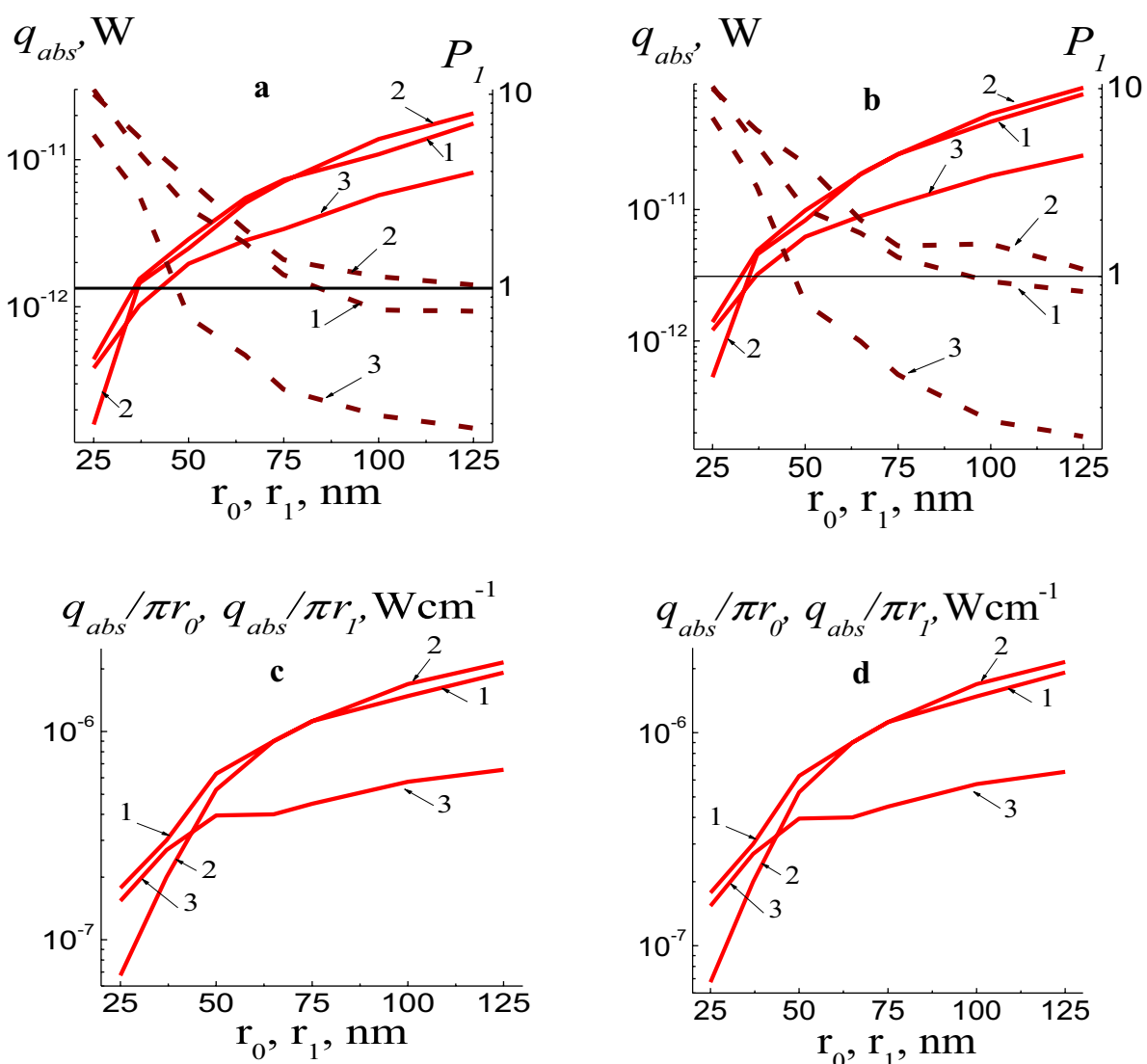

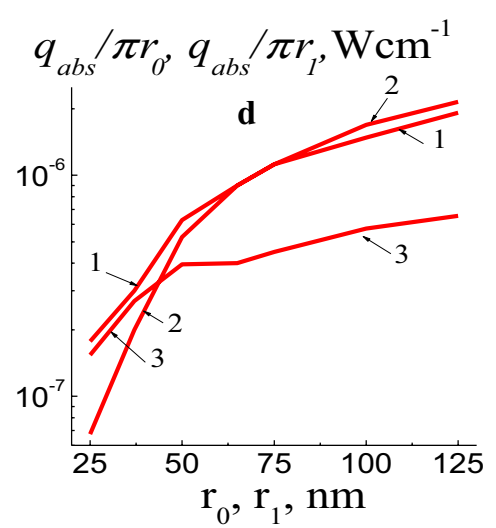

The difference in the values of $q_{\mathrm{abs}}$ for various Ti and $\mathrm{Ti}^{-\mathrm{TiO}_{2}} \mathrm{NPs}_{\text {with }}$ the radii $r_{0}, r_{1} \geq 50 \mathrm{~nm}$ is not very significant. The values of $q_{\mathrm{abs}}$ and $q_{\mathrm{abs}} / \pi r_{0}$ for Au are significantly smaller than these ones for $\mathrm{Ti}$ and $\mathrm{Ti}^{-} \mathrm{TiO}_{2}$ for $r_{0}, r_{1}>50 \mathrm{~nm}$. It is connected with the different optical properties of these NPs. It means that Au NPs can be used for absorption of solar radiation with comparative efficiency of $\mathrm{Ti}$ and $\mathrm{Ti}-\mathrm{TiO}_{2} \mathrm{NPs}$ only in the range of $r_{0} \leq 50 \mathrm{~nm}$. The values of $q_{\mathrm{abs}}$ and $q_{\mathrm{abs}} / \pi r_{0}, q_{\mathrm{abs}} / \pi r_{1}$ for Ti and $\mathrm{Ti}^{-\mathrm{TiO}_{2}}$ NPs in the spectral interval $200-2500 \mathrm{~nm}$ are larger than those in the interval $200-1100 \mathrm{~nm}$.

Parameter $P_{1}$ for NP determines the correlation between integral absorbed and scattered solar radiation by NP

$P_{1}=\frac{q_{\mathrm{abs}}}{q_{\mathrm{sca}}}$

$q_{\text {sca }}=\pi r_{0}^{2} \int_{\lambda_{1}}^{\lambda_{2}} I_{\mathrm{s}}(\lambda) K_{\text {sca }}\left(r_{0}, \lambda\right) \mathrm{d} \lambda$ is the integral of solar radiation power scattered by NP and analogous expression $q_{\text {sca }}$ for system of core-shell NPs with $r_{1}$. Parameters $P_{1}$ for $\mathrm{Ti}$ and $\mathrm{Ti}-\mathrm{TiO}_{2}$ NPs decrease from the values of about $\sim 10$ for $r_{0}, r_{1}=25 \mathrm{~nm}$ till the values of about $\sim 1$ with increasing $r_{0}, r_{1}$ till $r_{0}, r_{1}=125 \mathrm{~nm}$.

The increase in $r_{0}, r_{1}$ leads to the increase in $q_{\mathrm{abs}}$ and $q_{\mathrm{abs}} / \pi r_{0}, q_{\mathrm{abs}} / \pi r_{1}$, but to the decrease in $\mathrm{P}_{1}$, and taking into account their opposite influence, the maximal absorption efficiency could be achieved by appropriate selection of these parameters for various NPs.

The results of heating of homogeneous metallic and core-shell systems NPs and fluid [92-111] have been reviewed in this part. In general, next set of parameters determines the effective absorption and heating of NPs and fluid (NFs) $-q_{\mathrm{abs}}, r_{0}\left(r_{1}\right), N_{0}, c \rho, c_{\mathrm{m}} \rho_{\mathrm{m}^{\prime}}, k_{\mathrm{m}}, P_{1}$ [see (10-12)]. These results highlight the possibility for effective application of homogeneous $\mathrm{Ti}$ and core-shell $\mathrm{Ti}-\mathrm{TiO}_{2} \mathrm{NPs}$ with the radii of about $75-125 \mathrm{~nm}$ as effective absorbers of solar radiation and NF heaters.

It should be noted two problems that influence on thermal processes in NFs.

In general, NPs can initially have different sizes and the NP system is polydisperse one. In addition, even in the case of the initial monodisperse NP system, when all NPs have the same radii, various processes can occur in NF. NPs have a great tendency to collide and aggregate into larger clusters [75-77]. These also include the change in NPs size due to mechanical interaction between themselves and with the absorber walls, as well as the change (decrease) in NP sizes in high-temperature NFs due to evaporation and other processes [108]. 
Next problem is in the significant influence of NPs on physical and hydrodynamical properties of NFs in comparison with pure fluid. Last investigations of thermophysical, rheological and heat transfer properties of NFs for solar thermal applications are presented [112-118]. An investigation into the thermo-physical and rheological properties of NFs for solar thermal applications was carried out $[112,113]$. It was reviewed metal oxide NFs including formulation, thermo-physical properties, mechanisms and heat transfer performance [114]. The investigation of the transfer mechanisms in NFs has been carried out [115-118], including investigation of convective heat transfer of NFs, characterization of heat transfer (thermal conductivity) characteristics and thermo-physical properties of NFs and their applications.

These features influence on heating and thermal processes in NF, and it is necessary to carry out investigations further and to take into account the possible polydispersity and influence of NPs on NF when exposed to intense solar radiation.

\section{Applications of nanoparticles and nanofluids in solar thermal technologies}

Results of optical properties of NPs and heating of NPs by solar radiation can be used in various solar thermal technologies, thermal devices, solar absorption thermal collectors and other possible applications.

General problems and challenges of NPs applications in solar thermal collectors are in the increase in their efficiency of absorption and conversion of solar energy. The overviews of application of NPs and NFs in solar thermal collector and its challenges were presented [119-125] for the purpose to improve the performance of solar collectors.

Recent advances in optical nanostructures design and fabrication, using very specific technology, such as integrating nitrogen-doped graphitic carbon with Au NPs for excellent solar energy absorption properties [123], and applications of NFs for solar/thermal energy conversion are reviewed $[124,125]$. A review of economic feasibility and world scenario of solar water heating systems has been presented [122], and the importance of harvesting of solar radiation has been underlined.

The solar water heating systems are one of the most common applications of solar energy utilization. Such systems include flat plate and volumetric absorption solar collectors. Applications of NPs and NFs in flat plate solar collectors are investigated [126-130], including experimental evaluation of flat plate solar collector [127]. Effect of titanium dioxide/water NF use on thermal performance of the flat plate solar collector has been investigated [128]. Experimental and numerical investigations of the effect of $\mathrm{Al}_{2} \mathrm{O}_{3} / \mathrm{TiO}_{2}-\mathrm{H}_{2} \mathrm{O} \mathrm{NFs}$ on thermal efficiency of the flat plate solar collector have been carried out [129].

The use of NPs and NFs in direct absorption solar collectors is real challenge and very perspective for the performance of solar energy harvesting. Direct absorption solar collectors show great potential for efficient conversion of sunlight to thermal energy. Applications of NPs and NFs in direct solar absorption collectors are investigated and reviewed $[5,8,40,76,126,131-134]$. Part of these investigations was reviewed before. Recent investigations investigated applicability of various NPs for direct absorption solar collectors, including alumina $\mathrm{NF}$ and $\mathrm{ZnO}-\mathrm{Au}$ composite hierarchical particles dispersed in oil-based NFs [76, 131]. The optimization problems of a direct absorption solar collector with blended plasmonic NFs and effect of plasmonic nanoshell-based NF on efficiency of direct solar thermal collector were discussed $[132,133]$. The use of various NPs in flat plate and direct absorption solar collectors leads to increasing their thermal efficiency up to $10-15 \%$ in comparison with their collectors without NPs [126-134].

The last time the production of steam in thermal collectors under solar irradiation is very interesting field and a few investigations on this topic have been carried out $[111,135-138]$. Steam production is essential for a wide range of applications, and currently, there is a discussion if steam could be generated on top of heated NPs in a solar receiver. But in reality steam generation is mainly caused by localized boiling around the heated NPs and vaporization in the superheated region due to highly non-uniform temperature and radiation energy distribution. Steam generation under sun action and photothermal heating enabled by plasmonic NFs have been investigated taking into account the volumetric solar heating, direct solar steam generation and comparative study on solar evaporation via NPs.

Applications of NPs for solar chemical technologies are investigated the last time [139-145]. Many exciting possibilities exist to exploit the extremely large surface area-to-volume ratio of NPs to effect chemical reactions. These can be either thermo-chemical in nature, where the absorption of concentrated sunlight causes high temperatures that drive the reactions, or photocatalytic, where the NPs serve as photocatalysts for splitting water, waste remediation or other purposes. The review of experimental investigation on directly irradiated particles solar reactors has been presented [139]. Great interest is connected with the problems of photocatalysis with solar energy, including sunlight-responsive photocatalyst based on $\mathrm{TiO}_{2}$ for wastewater treatment [144] and photocatalytic water disinfection under solar irradiation by $\mathrm{Ag}_{0} \mathrm{TiO}_{2}$ core-shell structured NPs [145]. 
An important problem of water desalination is discussed [146] with application of recent freshwater augmentation techniques.

The novel performance and environmental effects of conventional and nanofluid-based thermal photovoltaics has been discussed [149].

The applications of NPs in various solar cells can be used for increasing cells efficiency and are discussed in [147-156]. General problems of the NPs use in solar cells are investigated [147-152] taking into account quantum-sized nanomaterials for solar cell applications [147], possible strategies and recent results in plasmonic enhanced solar cells [148], optimized $\mathrm{TiO}_{2}$ NPs packing for photovoltaic applications [150], performance enhancement of photovoltaic cells by changing configuration and using $\mathrm{Al}_{2} \mathrm{O}_{3}$ NPs [151] and influence of the $\mathrm{Cu}_{2} \mathrm{ZnSnS}_{4}$ NPs size on solar cell performance [152].

Hybrid solar cells from $\mathrm{Sb}_{2} \mathrm{~S}_{3}$ NP ink [153], device performance enhancement of polymer solar cells by NP selfassembly [154], plasmonic effect of gold NPs in organic solar cells [155] and novel synergistic combination of $\mathrm{Al} / \mathrm{N}$ Co-doped $\mathrm{TiO}_{2} \mathrm{NPs}$ for highly efficient dye-sensitized solar cells [156] were investigated and discussed.

For perovskite solar cells, NPs are used for the boosting efficiency of hole conductor-free cells by incorporating NiO NPs into carbon electrodes [157] and cobalt-doped nickel oxide NPs as efficient hole transport materials for low-temperature processed cells [158]. It is important that conversion efficiency of cells is improved to $14.5 \%$ [158] in comparison with previous investigations.

It should be noted that various NP applications in thermal solar technology can be used for the development of innovation devices or increasing efficiency existed technologies.

\section{Conclusions}

The present review is intended to bring the recent NP and $\mathrm{NF}$ optical properties and to summarize the latest thermal conversion and heating studies together with their application for direct absorption of solar radiation in order to facilitate the researchers and to realize the research potential in the field of NF-based absorber systems. This review can be considered as an important link between the optical properties of NPs and NFs and efficiency of NPs heating by solar energy. The results of systematic studies of all these characteristics have been presented as a prerequisite for the successful realization of the potential of selected NPs for solar thermal applications.

As commonly used working pure fluids are weak absorbers over the UV and VIS intervals of the solar spectrum, the addition of NPs has been proved to enhance the absorption characteristics of the base fluid. NPs offer the potential of improving the radiation properties of liquids, leading to a significant increase in the efficiency of thermal conversion of solar energy.

Although solar radiation absorption and thermal conversion by NPs and NFs are actively investigated in recent years, only a limited amount of the nearly unlimited potential combinations of NP structures, materials and sizes has been explored (as can be seen in the selected studies given in Tables 1,2 and 3). Additionally, little progress has been made toward the development of NP heating approaches.

Initially, an overview of the optical properties of metallic, oxide and hybrid core-shell NPs and characterization techniques is presented in this review. The latest numerical and experimental works and recent developments in the field of direct radiation absorption are summarized and discussed. This review provides a vital set of optical property data to enable further development of promising candidates for broadband and spectrally selective NF solar absorbers. Eventually, the present challenges and future possible directions are outlined.

An overview of the results of NP solar heating and thermal conversion is presented. Novel solar heating approaches have been formulated for NPs and NFs, which can be applied for effective conversion of solar radiation. Novel parameters $q_{a b s}$ and $P_{1}$ are introduced for the description of input solar energy in NP, which can be viewed as integral absorbed solar power, and the correlation between absorption and scattering of radiation by NP accordingly.

Presented discussions highlight the possibility to use metallic $\mathrm{Ti}$ and core-shell $\mathrm{Ti}^{-} \mathrm{TiO}_{2} \mathrm{NPs}$ as perspective absorbers of solar radiation and heating of NPs and NFs in the spectral interval $200-2500 \mathrm{~nm}$. Ti and $\mathrm{Ti}^{-} \mathrm{TiO}_{2} \mathrm{NPs}$ are available in the nanotechnology market and can be used for solar experiments. Furthermore, it is expected that the utilization of plasmonic Ni NPs, their core-shell structures and other NPs with controllable and broadband absorption properties over the entire solar spectrum attracts more attention.

There is also a need to optimize the NPs and NFs optical properties to ensure maximum thermal performance of the volumetric solar absorbers. Selection of suitable NPs includes the choice of their structure (homogeneous, core-shell, etc.), materials (metal, oxide, etc.), concentrations, sizes (their radii, thicknesses of oxide shells), optical indexes of absorption and refraction of NP material and surrounding medium, etc. and fluid (optical, thermophysical, etc.) parameters for effective absorption of solar radiation and their effective heating. NPs and NFs with the selected characteristics can realize their effective heating by solar radiation for solar thermal energy applications. 
These results are highlighting the use of established remarkable approaches that can improve current solar thermal technologies in near future.

The prominent advantage of this review in comparison with others is the right connection of optical properties of selected NPs with novel approach of NP heating and thermal conversion of solar radiation for achievement of maximal heating of NPs and NF. Overall, these results show great potential for the use of selected NPs and NFs in direct absorption solar thermal systems, and this is important for their further development and improvement. From the other side, further researches are required in the following experimental investigations to search more appropriate NPs for effective absorption and their heating and to enhance the efficiency of solar absorbers over the next several coming years.

\section{Compliance with ethical standards}

Conflict of interest The author declares that he has no conflict of interest.

\section{References}

1. Renewables 2018 (2017) Global status report (GSR)

2. Kalogirou SA (2013) Solar energy engineering: processes and systems, 2nd edn. Academic Press, Cambridge

3. Masud M, Khan K, Chowdhury A, Sayeed Hassan N (eds) (2017) Application of thermo-fluid processes in energy systems: key issues and recent developments for a sustainable future. Springer, Berlin

4. Agrawal G, Khatri R (2016) Solar thermal collectors: direct absorption using nanofluids: enhancing thermal performance by reducing heat losses and improving fluid properties. Lap Lambert Academic Publishing, Riga

5. Phelan P, Otanicar T, Taylor R, Tyagi H (2013) Trends and opportunities in direct absorption solar thermal collectors. J Therm Sci Eng Appl 5:021003

6. ASTM G173-03 (2012) Standard tables for reference solar spectral irradiances: direct normal and hemispherical on $37^{\circ}$ tilted surface. ASTM International, West Conshohocken

7. Born M, Wolf E (1964) Principles of optics. Pergamon Press, Oxford

8. Hale G, Querry M (1973) Optical constants of water in the 250-nm to 250- $\mu \mathrm{m}$ wavelength region. Appl Opt 12:555-562

9. Saidur R, Meng T, Said Z, Hasanuzzaman M, Kamyar C (2012) A evaluation of the effect of NF-based absorbers on direct solar collector. Int J Heat Mass Transf 55:5899-5907

10. Tang Y, Vlahovic B (2013) Metallic nanoparticles for trapping light. Nanoscale Res Lett 8:65-72

11. Reddy KS, Kamnapure NR, Srivastava S (2017) Nanofluid and nanocomposite applications in solar energy conversion systems for performance enhancement: a review. Int J LowCarbon Technol 12:1-23

12. Jones MR, Osberg KD, Macfarlane RJ, Langille MR, Mirkin CA (2011) Templated techniques for the synthesis and assembly of plasmonic nanostructures. Chem Rev 111:3736-3827
13. Aliofkhazraei M (ed) (2016) Handbook of NPs. Springer, Heidelberg

14. Makhlouf A, Barhoum A (eds) (2018) Fundamentals of nanoparticles: classifications, synthesis methods, properties and characterization. Elsevier, Amsterdam

15. Kreibig U, Vollmer M (1995) Optical properties of metal clusters. Springer, Heidelberg

16. Bohren CF, Huffman DR (1983) Absorption and scattering of light by small particles. Wiley, New York

17. Mayergoyz I (2013) Plasmon resonances in nanoparticles. World Scientific Publishing, Singapore

18. Coronado EA, Encina ER, Stefani FD (2011) Optical properties of metallic nanoparticles: manipulating light, heat and forces at the nanoscale. Nanoscale 3:4042-4054

19. Crut A, Maioli P, Del Fatti N, Vallée F (2014) Optical absorption and scattering spectroscopies of single nano-objects. Chem Soc Rev 43:3921-3956

20. Pustovalov VK (2016) Thermo-optical properties of spherical homogeneous and core-shell nanoparticles and their applications. In: Aliofkhazraei M (ed) Handbook of nanoparticles. Springer, Heidelberg, pp 819-841

21. Gaponenko SV (2010) Introduction to nanophotonics. Cambridge University Press, Cambridge

22. Trugler A (2016) Optical properties of metallic nanoparticles. Springer, Heidelberg

23. West PR, Ishii S, Naik GV, Emani NK, Shalaev VM, Boltasseva A (2010) Searching for better plasmonic materials. Laser Photonics Rev 6:795-808

24. Butet J, Yang K-Y, Dutta-Gupta S, Martin O (2016) Maximizing nonlinear optical conversion in plasmonic nanoparticles through ideal absorption of light. ACS Photonics 3:1453-1459

25. Grigoriev V, Bonod N, Wenger J, Stout B (2015) Optimizing nanoparticle designs for ideal absorption of light. ACS Photonics 2:263-270

26. Chen L, Xu C, Liu J, Fang X, Zhang Z (2017) Optical absorption property and photo-thermal conversion performance of graphene oxide/water nanofluids with excellent dispersion stability. Sol Energy 148:17-24

27. Fan D, Li Q, Chen W, Zeng J (2017) Graphene nanofluids containing core-shell nanoparticles with plasmon resonance effect enhanced solar energy absorption. Sol Energy 158:1-8

28. Rose B, Singh H, Verma N, Tassou S, Suresh S, Anantharaman N, Mariotti D, Maguired P (2017) Investigations into nanofluids as direct solar radiation collectors. Sol Energy 147:426-431

29. Anderson LJ, Mayer KM, Fraleigh RD, Yang Y, Lee S, Hafner JN (2010) Quantitative measurements of individual gold nanoparticle scattering cross sections. J Phys Chem C 114:11127-11132

30. Pustovalov V, Astafyeva L, Fritzsche W (2012) Comparative analysis of thermo-optical properties of metallic nanoparticles for photonic applications in nanotechnology. Sci Adv Mater 4:480-488

31. Moreira LM, Carvalho E, Bell M, Anjos V, Sant'Ana A, Alves A et al (2013) Thermooptical properties of silver and gold nanofluids. J Therm Anal Calorim 114:557-564

32. Jiang K, Smith D, Pinchuk A (2013) Size-dependent photothermal conversion efficiencies of plasmonically heated gold NPs. J Phys Chem C 117:27073-27078

33. Pustovalov V, Astafyeva L, Fritzsche W (2015) Analysis of optical properties of spherical metallic nanoparticles for effective absorption of solar radiation and their heating. Sol Energy 122:1334-1341

34. Jin H, Lin G, Bai L, Amjad M, Bandarra C, Filho E, Wen D (2016) Photothermal conversion efficiency of nanofluids: an experimental and numerical study. Sol Energy 139:278-289 
35. Chen M, He Y, Zhu J, Kim DR (2016) Enhancement of photothermal conversion using gold nanofluids with different particle sizes. Energy Convers Manag 112:21-30

36. Qin Z, Wang Y, Randrianalisoa J, Raeesi V, Chan WCC, Lipinski W, Bischof JC (2016) Quantitative comparison of photothermal heat generation between gold nanospheres and nanorods. Sci Rep 6:29836

37. Astafyeva L, Pustovalov V, Fritzsche W (2017) Characterization of plasmonic and thermo-optical parameters of spherical metallic nanoparticles. Nano-Struct Nano-Objects 12:57-67

38. Holm V, Greve M, Holst B (2017) A theoretical investigation of the optical properties of metal nanoparticles in water for photo thermal conversion enhancement. Energy Convers Manag 149:536-542

39. Chen M, He Y, Wang X, Hu Y (2018) Numerically investigating the optical properties of plasmonic metallic NPs for effective solar absorption and heating. Sol Energy 161:17-24

40. Taylor R, Phelan P, Otanicar T, Adrian R, Prasher R (2011) Nanofluid optical property characterization: towards efficient direct absorption solar collectors. Nanoscale Res Lett 6:1-11

41. Pustovalov VK, Astafyeva LG (2013) Investigation of thermooptical characteristics of the interaction processes of laser radiation with silver nanoparticles. Laser Phys 23:065901

42. Otanicar T, Hoyt J, Fahar M, Jiang X, Taylor RA (2013) Experimental and numerical study on the optical properties and agglomeration of nanoparticle suspensions. J Nanopart Res 15:1-11

43. Gorji T, Ranjbar A (2016) A numerical and experimental investigation on the performance of a low-flux direct absorption solar collector (DASC) using graphite, magnetite and silver nanofluids. Sol Energy 135:493-505

44. Saidur R, Meng T, Said Z, Hasanuzzaman M, Kamyar A (2012) Evaluation of the effect of nanofluid-based absorbers on direct solar collector. Int J Heat Mass Transf 55:5899-5907

45. Zhu Q, Cui Y, Mu L, Tang L (2013) Characterization of thermal radiative properties of nanofluids for selective absorption of solar radiation. Int J Thermophys 34:2307-2321

46. Kameya Y, Hanamura K (2011) Enhancement of solar radiation absorption using nanoparticle suspension. Sol Energy 85:299-307

47. Zhang L, Liu J, He G, Ye Z, Fang X, Zhang Z (2014) Radiative properties of ionic liquid based nanofluids for medium-tohigh-temperature direct absorption solar collectors. Sol Energy Mater Sol Cells 130:521-528

48. Dang T, Le T, Fribourg-Blanc E, Dang MC (2011) Synthesis and optical properties of copper nanoparticles prepared by a chemical reduction method. Adv Nat Sci Nanosci Nanotechnol 2:015009

49. He Q, Wang S, Zeng S, Zheng Z (2013) Experimental investigation on photothermal properties of nanofluids for direct absorption solar thermal energy systems. Energy Convers Manag 73:150-157

50. Astafyeva L, Pustovalov V (2016) Angular optical characteristics of light scattered by double-layer metal-oxide nanoparticles. Opt Spectrosc 121:109-114

51. Refractive index database (2018) http://refractiveindex.info/

52. Palik ED (ed) (1997) Handbook of optical constants of solid. Academic Press, New York

53. Bardhan R, Grady NK, Ali T, Halas NJ (2010) Metallic nanoshells with semiconductor cores: optical characteristics modified by core medium properties. ACS Nano 4:6169-6179

54. Lee BJ, Park K, Walsh T, Xu L (2012) Radiative heat transfer analysis in plasmonic nanofluids for direct solar thermal absorption. J Sol Energy Eng 134:021009

55. Ghazanfari L, Khosroshahi ME (2014) Simulation and experimental results of optical and thermal modeling of gold nanoshells. Mater Sci Eng, C 42:185-191
56. Lv W, Phelan PE, Swaminathan R, Otanicar TP, Taylor RA (2013) Multifunctional core-shell nanoparticle suspensions for efficient absorption. J Sol Energy Eng 135:021004

57. Wu Y, Zhou L, Du X, Yang Y (2015) Optical and thermal radiative properties of plasmonic nanofluids containing core-shell composite NPs for efficient photothermal conversion. Int J Heat Mass Transf 82:545-554

58. Pustovalov V, Astafyeva L, Fritzsche W (2012) Optical properties of core-shell gold-silver and silver-gold nanoparticles for near UV and visible radiation wavelengths. Plasmonics 7:469-474

59. Byers C, Zhang H, Swearer D, Yorulmaz M, Hoener B, Huang D et al (2015) From tunable core-shell NPs to plasmonic drawbridges: active control of nanoparticle optical properties. Sci Adv 1:e1500988

60. Laaksonen K, Suomela S, Puisto S, Rostedt N, Ala-Nissila T, Nieminen R (2013) Influence of high-refractive-index oxide coating on optical properties of metal nanoparticles. J Opt Soc Am B 30:338-343

61. Ruffino F, Piccitto G, Grimaldi M (2014) Simulations of the light scattering properties of metal/oxide core/shell nanospheres. J Nanosci 2014:407670

62. Menbari A, Alemrajabi AA (2016) Analytical modeling and experimental investigation on optical properties of new class of nanofluids $\left(\mathrm{Al}_{2} \mathrm{O}_{3}-\mathrm{CuO}\right.$ binary nanofluids) for direct absorption solar thermal energy. Opt Mater 52:116-125

63. Pustovalov V, Bobuchenko D (1988) Heating and ignition of aerosol particles in a gas by intense optical radiation. Combust Explos Shock Waves 24:317-324

64. Pustovalov V, Astafyeva L (2015) Influence of shell parameters on optical properties of spherical metallic core-oxide shell nanoparticles. J Nanomater 2015:812617

65. Pustovalov VK, Astafyeva LG, Fritzsche W (2018) Optical properties of nanoparticles and nanofluids for direct absorption of solar radiation. Nanotechnol Environ Eng 3:15

66. Pustovalov VK, Astafyeva LG, Fritzsche W (2017) Light-absorption selection of NPs and nanofluids containing NPs for their effective heating by solar radiation. Nanotechnol Environ Eng 2:7

67. Pustovalov V, Astafyeva L (2017) Spectral properties of nanofluids with homogeneous and bilayer nanoparticles for efficient absorption of solar radiation. Opt Spectrosc 123:158-163

68. Zhang L, Wang H (2011) Cupruos oxide nanoshells with geometrically tunable optical properties. ACS Nano 5:3257-3267

69. Genc A, Patarroyo J, Sancho-Parramon J, Basts N, Puntes V, Arbiol J (2017) Hollow metal nanostructures for enhanced plasmonics: synthesis, local plasmonic properties and applications. Nanophotonics 6:193-213

70. Pustovalov V, Astafyeva L, Zharov V (2013) Dependences of optical properties of spherical two-layered NPs on parameters of gold core and material shell. J Quant Spectrosc Radiat Transf 131:121-129

71. Vaidya S, Patra A, Ganguli AK (2012) Optical properties of Ag@ $\mathrm{TiO}_{2}$ and $\mathrm{CdS} @ \mathrm{TiO}_{2}$ core-shell nanostructures. Sci Adv Mater 4:631-636

72. Yorulmaz A, Nizzero S, Hoggard A, Wang L-Y, Cai Y-Y, Su M-N et al (2015) Single-particle absorption spectroscopy by photothermal contrast. Nano Lett 15:3041-3048

73. Said Z, Saidur R, Rahim N (2014) Optical properties of metal oxides based nanofluids. Int Commun Heat Mass Transf 59:46-54

74. Milanese M, Colangelo G, Creti A, Lomascolo M, lacobazzi F, de Risi A (2016) Optical absorption measurements of oxide NPs for application as NF in direct absorption solar power systemspart 1: water-based nanofluids behavior. Sol Energy Mater Sol Cells 147:315-320 
75. Sajid M, Said Z, Saidur R, Adikan F, Sabri M, Rahim N (2014) A time variant investigation on optical properties of water based $\mathrm{Al}_{2} \mathrm{O}_{3}$ nanofluid. Int Commun Heat Mass Transf 50:108-116

76. Sajid M, Said Z, Saidur R, Sabri M (2015) Applicability of alumina nanofluid in direct absorption solar collectors. Appl Mech Mater 699:366-371

77. Song D, Wang Y, Jing D, Geng J (2016) Investigation and prediction of optical properties of alumina nanofluids with different aggregation properties. Int J Heat Mass Transf 96:430-437

78. Zhu Q, Cui Y, Mu L, Tang L (2013) Characterization of thermal radiative properties of nanofluids for selective absorption of solar radiation. Int J Thermophys 34:2307-2321

79. Karami M, Akhavan-Behabadi M, Dehkordi MR, Delfani S (2016) Thermo-optical properties of copper oxide nanofluids for direct absorption of solar radiation. Sol Energy Mater Sol Cells 144:136-142

80. Kasaeian A, Eshghi AT, Sameti M (2015) A review on the applications of nanofluids in solar energy systems. Renew Sustain Energy Rev 43:584-598

81. Jianyu T, Yinmo X, Fuqiang W, Lin J, Lanxin M (2017) Investigation of optical properties and radiative transfer of $\mathrm{TiO}_{2}$ nanofluids with the consideration of scattering effects. Int J Heat Mass Transf 115:1103-1112

82. Devore JR (1951) Refractive indices of rutile and sphalerite. J Opt Soc Am 41:416-419

83. Mahmoud S, Alshomer S, Tarawnh M (2011) Structural and optical characterization of spayed nickel oxide thin films. J Mod Phys 2:1178-1186

84. Gorji TB, Ranjbar AA (2017) A review on optical properties and application of nanofluids in direct absorption solar collectors (DASCs). Renew Sustain Energy Rev 72:10-32

85. Ahmad S, Saidur R, Mahbubul I, Al-Sulaiman A (2017) Optical properties of various nanofluids used in solar collector: a review. Renew Sustain Energy Rev 73:1014-1030

86. Said Z, Aaidur MH, Kamalisarvestani M, Rahim NA (2013) Radiative properties of nanofluids. Int J Heat Mass Transf 46:74-84

87. Hossain M, Saidur R, Sabri M, Said Z, Hassani S (2015) Spotlight on available optical properties and models of nanofluids: a review. Renew Sustain Energy Rev 43:750-762

88. Mehrali M, Ghatkesar M, Pecnik R (2018) Full-spectrum volumetric solar thermal conversion via graphene/silver hybrid plasmonic nanofluids. Appl Energy 224:103-115

89. Du M, Tang GH (2015) Optical property of nanofluids with particle agglomeration. Sol Energy 122:864-872

90. Guo CF, Sun T, Cao F, Lui Q, Ren Z (2014) Metallic nanostructures for light trapping in energy-harvesting devices. Sci Appl 3:1-12

91. Encina E, Coronado E (2016) Size optimization of iron oxide@ noble metal core-shell nanohybrids for photothermal applications. J Phys Chem C 120:5630-5639

92. Joseph S, Mathew S, Sharma G, Hari M, Kurian A, Radhakrishnan P, Nampoori V (2010) Photothermal characterization of nanogold under conditions of resonant excitation and energy transfer. Plasmonics 5:63-68

93. Chen H, Shao L, Ming T, Sun Z, Zhao C, Yang B, Wang J (2010) Understanding the photothermal conversion efficiency of gold nanocrystals. Small 6:2272-2280

94. Pustovalov V (2011) Modeling of the processes of laser-nanoparticle interaction taking into account temperature dependences of parameters. Laser Phys 21:906-912

95. Pustovalov V, Astafyeva L, Fritzsche W (2013) Selection of thermo-optical parameter of nanoparticle for achievement of their maximal thermal energy under optical irradiation. Nano Energy 2:1137-1141

96. Zhang H, Chen H, Du X, Wen D (2014) Photothermal conversion characteristics of gold nanoparticle dispersions. Sol Energy 100:141-147

\section{SN Applied Sciences}

97. Pustovalov V (2018) Heating of single nanoparticles, their assemblies and ambient medium by solar radiation. Nanotechnol Environ Eng 3:7

98. Karampelas IH, Alali KL, Furlani EP (2016) Plasmonic nanoframes for photothermal energy conversion. J Phys Chem C 120:7256-7264

99. Pustovalov VK (2016) Light-to-heat conversion and heating of single NPs, their assemblies, and surrounding medium under laser pulses. RSC Adv 6:81266-81289

100. Chen M, He Y, Huang J, Zhu J (2017) Investigation into Au nanofluids for solar photothermal conversion. Int J Heat Mass Transf 108 B:1894-1900

101. Duan H, Tang L, Zheng Y, Zhang P (2018) Optical and thermal enhancement of plasmonic nanofluid based on core/shell NPs. Plasmonics 13:1135-1141

102. Ponseca C, Chábera P, Uhlig J, Persson P, Sundström V (2017) Ultrafast electron dynamics in solar energy conversion. Chem Rev 117:10940-11024

103. Gupta M, Ungaro C, FoleyIV J, Gray S (2018) Review Optical nanostructures design, fabrication, and applications for solar/thermal energy conversion. Sol Energy 165:100-114

104. Yu X, Xuan Y (2018) Investigation on thermo-optical properties of $\mathrm{CuO} / \mathrm{Ag}$ plasmonic nanofluids. Sol Energy 160:200-207

105. Rativa D, Gómez-Malagón L (2018) Colloidal plasmonic structures for harvesting solar radiation. Renew Energy 118:947-954

106. Amjad M, Jin H, Du X, Wen D (2018) Experimental photothermal performance of nanofluids under concentrated solar flux. Sol Energy Mater Sol Cells 182:255-262

107. Pustovalov V (2018) Heating of single NPs, their assemblies and ambient medium by solar radiation. Nanotechnol Environ Eng 3:7

108. Kreith F, Black WZ (1980) Basic heat transfer. Harper and Row, New York

109. Guo A, Fu Y, Wang G, Wang X (2017) Diameter effect of gold nanoparticles on photothermal conversion for solar steam generation. RSC Adv 7:4815-4823

110. Ishii S, Sugavaneshwar RP, Chen K, Dao TD, Nagao T (2016) Solar water heating and vaporization with silicon NPs at Mie resonances. Opt Mater Express 6:640-648

111. Amjad M, Raza G, Xin Y, Pervaiz S, Xu J, Du X, Wen D (2017) Volumetric solar heating and steam generation via gold nanofluids. Appl Energy 206:393-400

112. Arthur O, Karim MA (2016) An investigation into the thermophysical and rheological properties of nanofluids for solar thermal applications. Renew Sustain Energy Rev 55:739-755

113. Sharmaa AK, Tiwarib AK, Dixit AR (2016) Rheological behavior of nanofluids: a review. Renew Sustain Energy Rev 53:779-791

114. Suganthi K, Rajan K (2017) Metal oxide NFs: review of formulation, thermo-physical properties, mechanisms, and heat transfer performance. Renew Sustain Energy Rev 76:226-255

115. Gupta M, Singh V, Kumar R, Said Z (2017) A review on thermophysical properties of nanofluids and heat transfer applications. Renew Sustain Energy Rev 74:638-670

116. Vanakia SM, Ganesana P, Mohammed HA (2016) Numerical study of convective heat transfer of nanofluids: a review. Renew Sustain Energy Rev 54:1212-1239

117. Leong K, Ahmad K, Ong H, Ghazali M, Baharum A (2017) Synthesis and thermal conductivity characteristic of hybrid nanofluids-a review. Renew Sustain Energy Rev 75:868-878

118. Ganvir R, Walke P, Kriplani V (2017) Heat transfer characteristics in nanofluid-a review. Renew Sustain Energy Rev 75:451-460

119. Hussein AK (2016) Applications of nanotechnology to improve the performance of solar collectors-recent advances and overview. Renew Sustain Energy Rev 62:767-792 
120. Leong K, Ong HC, Amer NH, Norazrina MJ, Risby MS (2016) An overview on current application of nanofluids in solar thermal collector and its challenges. Renew Sustain Energy Rev 53:1092-1105

121. Leung SF, Zhang Q, Tavakoli MM, He J, Mo X, Fan Z (2016) Progress and design concerns of nanostructured solar energy harvesting devices. Small 12:12537-12545

122. Gautam A, Chamoli S, Kumar A, Singh S (2017) A review on technical improvements, economic feasibility and world scenario of solar water heating system. Renew Sustain Energy Rev 68:541-562

123. Lingling W, Guihua Z, Wei Y, Jia Z, Huaqing X (2018) Integrating nitrogen-doped graphitic carbon with Au NPs for excellent solar energy absorption properties. Sol Energy Mater Sol Cells 184:1-8

124. Gupta M, Ungaro C, Foley J, Gray S (2018) Optical nanostructures design, fabrication, and applications for solar/thermal energy conversion. Sol Energy 165:100-114

125. Elsheikh H, Sharshir S, Mostafa M, Essa F, Kamal M, Ali A (2018) Applications of nanofluids in solar energy: a review of recent advances. Renew Sustain Energy Rev 82:3483-3502

126. Raj P, Subudhi S (2018) A review of studies using nanofluids in flat-plate and direct absorption solar collectors. Renew Sustain Energy Rev 84:54-74

127. Verma SK, Tiwari AK, Chauhan DS (2017) Experimental evaluation of flat plate solar collector using NFs. Energy Convers Manag 134:103-115

128. Kiliç F, Menlik T, Sözen A (2018) Effect of titanium dioxide/water nanofluid use on thermal performance of the flat plate solar collector. Sol Energy 164:101-108

129. Farajzadeh $E$, Movahed $S$, Hosseini $R$ (2018) Experimental and numerical investigations on the effect of $\mathrm{Al}_{2} \mathrm{O}_{3} / \mathrm{TiO}_{2}-\mathrm{H}_{2} \mathrm{O}$ nanofluids on thermal efficiency of the flat plate solar collector. Renew Energy 118:122-130

130. Asmussen S, Vallo C (2018) Absorber materials based on polymer nanocomposites containing silver NPs for solar thermal collectors. Sol Energy 174:640-647

131. Wang $X$, He Y, Chen M, Hu Y (2018) ZnO-Au composite hierarchical particles dispersed oil-based nanofluids for direct absorption solar collectors. Sol Energy Mater Sol Cells 179:185-193

132. Qin C, Kang K, Lee I, Jae B, Lee C (2017) Optimization of a direct absorption solar collector with blended plasmonic nanofluids. Sol Energy 150:512-520

133. Duan H, Tang L, Zheng Y, Xu C (2018) Effect of plasmonic nanoshell-based nanofluid on efficiency of direct solar thermal collector. Appl Therm Eng 133:188-193

134. Bhalla V, Tyagi H (2018) Parameters influencing the performance of NPs-laden fluid-based solar thermal collectors: a review on optical properties. Renew Sustain Energy Rev 84:12-42

135. Ni G, Li G, Boriskina S, Li H, Yang W, Zhang T, Chen G (2016) Steam generation under one sun and ambient conditions. Nat Energy 1:16126

136. Wang X, He Y, Liu X, Shi L, Zhu J (2017) Investigation of photothermal heating enabled by plasmonic nanofluids for direct solar steam generation. Sol Energy 157:35-46

137. Zeiny A, Jin H, Lin G, Song P, Wen D (2018) Solar evaporation via nanofluids: a comparative study. Renew Energy 122:443-454

138. Huang J, He Y, Chen M, Jiang B, Huang Y (2017) Solar evaporation enhancement by a compound film based on $\mathrm{Au} @ \mathrm{TiO}_{2}$ core-shell NPs. Sol Energy 155:1225-1232

139. Alonso E, Romero M (2015) Review of experimental investigation on directly irradiated particles solar reactors. Renew Sustain Energy Rev 41:53-67

140. Keane D, McGuigan K, Fernandez-Ibanez P, Pillai S (2014) Solar photocatalysis for water disinfection: materials and reactor design. Catal Sci Technol 4:1211-1226
141. Jadhav N, Gondhalekar K, Doltade S, Pinjari D (2018) Concentrated solar radiation aided green approach towards the synthesis of $\mathrm{Fe}_{3} \mathrm{O}_{4} \mathrm{NPs}$ by photochemical oxidation of $\mathrm{FeCl}_{2}$. Sol Energy 171:769-773

142. Ong C, $\mathrm{Ng} \mathrm{L}$, Mohamma A (2018) A review of $\mathrm{ZnO}$ NPs as solar photocatalysts: synthesis, mechanisms and applications. Renew Sustain Energy Rev 81:536-551

143. Bora L, Mewada R (2017) Visible/solar light active photocatalysts for organic effluent treatment: fundamentals, mechanisms and parametric review. Renew Sustain Energy Rev 76:1393-1421

144. Borgesa ME, Sierra M, Cuevas E, García RD, Esparza P (2016) Photocatalysis with solar energy: sunlight-responsive photocatalyst based on $\mathrm{TiO}_{2}$ loaded on a natural material for waste water treatment. Sol Energy 135:527-535

145. Sreeja S, Shetty V (2017) Photocatalytic water disinfection under solar irradiation by $\mathrm{Ag} @ \mathrm{TiO}_{2}$ core-shell structured NPs. Sol Energy 157:236-243

146. Srithar K, Rajaseenivasan T (2018) Recent fresh water augmentation techniques in solar still and $\mathrm{HDH}$ desalination-a review. Renew Sustain Energy Rev 82:629-644

147. Kumar S, Nehra M, Deep A, Kedia D, Kim K-H (2017) Quantumsized nanomaterials for solar cell applications. Renew Sustain Energy Rev 73:821-839

148. Enrichi F, Quandt A, Righini G (2018) Plasmonic enhanced solar cells: summary of possible strategies and recent results. Renew Sustain Energy Rev 82:2433-2439

149. Said Z, Arora S, Bellos E (2018) A review on performance and environmental effects of conventional and nanofluid-based thermal photovoltaics. Renew Sustain Energy Rev 94:302-316

150. Taleb A, Mesguich F, Hérissan A, Colbeau-Justin C, Dubot $P$ (2016) Optimized $\mathrm{TiO}_{2}$ nanoparticle packing for DSSC photovoltaic applications. Sol Energy Mater Sol Cells 48:52-59

151. Abdelrahman $H$, Wahba $M$, Refaey $H$, Moawad $M$, Berbish N (2019) Performance enhancement of photovoltaic cells by changing configuration and using PCM (RT35HC) with $\mathrm{NPs} \mathrm{Al}_{2} \mathrm{O}_{3}$. Sol Energy 177:665-671

152. Ananthoju B, Mohapatra J, Bahadur D, Medhekar N, Aslam M (2019) Influence of the $\mathrm{Cu}_{2} \mathrm{ZnSnS}_{4}$ NPs size on solar cell performance. Sol Energy Mater Sol Cells 189:125-132

153. Wang W, Strössner F, Zimmermann E, Schmidt-Mende L (2017) Hybrid solar cells from $\mathrm{Sb}_{2} \mathrm{~S}_{3}$ nanoparticle ink. Sol Energy Mater Sol Cells 172:335-340

154. Zhang W, Nguyen N, Murray R, Mackay M (2017) Device performance enhancement of polymer solar cells by nanoparticle self-assembly. Sol Energy Mater Sol Cells 160:126-133

155. Notarianni M, Vernon K, Chou A, Aljada M, Motta N (2014) Plasmonic effect of gold nanoparticles in organic solar cells. Sol Energy 106:23-37

156. Dhonde K, Dhonde M, Murty V (2018) Novel synergistic combination of $\mathrm{Al} / \mathrm{N}$ Co-doped $\mathrm{TiO}_{2} \mathrm{NPs}$ for highly efficient dyesensitized solar cells. Sol Energy 173:551-557

157. Chu L, Liu W, Qin Z, Zhang R, Li X (2018) Boosting efficiency of hole conductor-free perovskite solar cells by incorporating p-type $\mathrm{NiO}$ nanoparticles into carbon electrodes. Sol Energy Mater Sol Cells 178:164-169

158. Kaneko R, Chowdhury T, Wu G, Kayesh M, Otsuki J (2019) Cobalt-doped nickel oxide NPs as efficient hole transport materials for low-temperature processed perovskite solar cells. Sol Energy 181:243-250

Publisher's Note Springer Nature remains neutral with regard to jurisdictional claims in published maps and institutional affiliations. 